Discussion Paper No. 04-33

Are Skill Requirements in the

Workplace Rising?

Stylized Facts and Evidence on Skill-Biased Technological Change

Alexandra Spitz

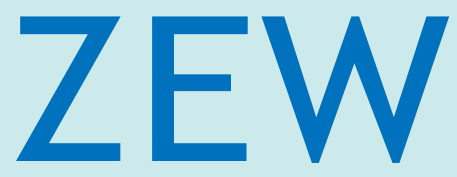

Zentrum für Europäische Wirtschaftsforschung $\mathrm{GmbH}$

Centre for European

Economic Research 
Discussion Paper No. 04-33

\title{
Are Skill Requirements in the Workplace Rising? Stylized Facts and Evidence on Skill-Biased Technological Change
}

\author{
Alexandra Spitz
}

Download this ZEW Discussion Paper from our ftp server:

\author{
ftp://ftp.zew.de/pub/zew-docs/dp/dp0433.pdf
}

\begin{abstract}
Das Papier entstand im Rahmen des Forschungsprojekts „Informationstechnologien, Arbeitsplatzorganisation und qualifikatorische Lohnstruktur“ im Auftrag der Landesstiftung Baden-Württemberg.
\end{abstract}

The paper was written as part of the research project "ICT, Work Organization, and Wages Across and Within Skill Groups" commissioned by the Landesstiftung Baden-Württemberg foundation.

Die Discussion Papers dienen einer möglichst schnellen Verbreitung von neueren Forschungsarbeiten des ZEW. Die Beiträge liegen in alleiniger Verantwortung der Autoren und stellen nicht notwendigerweise die Meinung des ZEW dar.

Discussion Papers are intended to make results of ZEW research promptly available to other economists in order to encourage discussion and suggestions for revisions. The authors are solely responsible for the contents which do not necessarily represent the opinion of the ZEW. 


\section{Non-technical Summary}

The effect of technological change on the labor market has always been a major concern of economic research. Interest has intensified in the last two decades with the observation that both employees with high levels of education and information technology are becoming more important at the workplace. This development led to the hypothesis that recent technological change has been non-neutral, increasing the productivity of highly skilled employees more than that of less skilled employees.

The literature so far found evidence on various aggregation levels that supports this hypothesis. However, there is little direct evidence on how occupational skill requirements have changed in recent decades. The present analysis aims at closing this gap by investigating skill requirements at the workplace, measured directly by the task-composition of occupations.

The analysis shows that skill requirements at the workplace have increased in West Germany between 1979 and 1999, owing to a shift toward analytical and interactive activities and away from cognitive and manual routine activities. This skill upgrading has also occurred within detailed education and age groups. A numerical assessment shows that changing occupational skill requirements account for nearly 50 percent of the educational upgrading in recent decades. Given that the analysis focuses solely on the within-occupational changes in task inputs neglecting the large shifts in the occupational distribution in employment toward more skill demanding occupations such as professionals and managers, this figure is significant.

The paper additionally includes direct evidence on the role workplace computerization has had in this development. The results suggest that computer technology substitutes for workers in performing manual and cognitive routine tasks, whereas it complements workers in performing non-routine cognitive tasks. This relationship is found within occupations, within occupation-education groups and within occupation-age groups.

The overall result that occupations today require more skills than 20 years ago emphasizes the importance of education and training in order to enable employees to cope with the challenges brought about by the changing task composition of occupations. It draws a particularly pessimistic perspective for the labor market prospects of employees with low levels of education. This group of employees has experienced the least favorable labor market development in recent decades. It has experienced either a decrease in wages or has been crowded out of the labor market in most industrialized countries. As the skill level of employees with low levels of education no longer meets the minimum occupational skill requirements, they become increasingly marginalized. 


\title{
Are Skill Requirements in the Workplace Rising? Stylized Facts and Evidence on Skill-Biased Technological Change
}

\author{
AleXANDRA SPITZ \\ Centre for European Economic Research (ZEW), Mannheim
}

January 2004

\begin{abstract}
The present analysis investigates skill requirements in the workplace, measured directly by the task-composition of occupations. It shows that the task composition of occupations has shifted toward analytical and interactive activities and away from manual and cognitive routine activities in West Germany between 1979 and 1999. These withinoccupational task changes account for around 50 percent of the educational upgrading in recent decades. The analysis shows additionally that computer technology is complementary to workers in executing analytical and interactive activities, whereas it substitutes for workers in performing manual and cognitive routine tasks. This relationship exists within occupations, within occupation-education groups and within occupation-age groups.
\end{abstract}

JEL classification: O30, J23

Keywords: occupational skill requirements, skill-biased technological change

Address: Centre for European Economic Research (ZEW)

Research Group Information and Communication Technologies

P.O. Box 103443

D-68034 Mannheim

Germany

Phone: $\quad+49 / 621 / 1235-293$

Fax: $\quad+49 / 621 / 1235-333$

E-Mail: spitz@zew.de

Acknowledgments: The paper was written as part of the research project "ICT, Workplace Organization, and Wages Across and Within Skill Groups" commissioned by the Landesstiftung Baden-Württemberg foundation. I thank David Autor for invaluable guidance throughout the thinking and writing of this paper. I am also indebted to Daron Acemoglu, Miriam Beblo, Irene Bertschek, Lex Borghans, Bernd Fitzenberger, Thomas Hempell, Ulrich Kaiser, Frank Levy, Elisabeth Mueller, Jörn-Steffen Pischke, Bas ter Weel, Elke Wolf and participants at the MIT labor lunch seminar for their suggestions and comments. 


\section{Introduction}

In recent decades industrialized countries have witnessed both a major increase in the supply of more educated workers and rising returns to education. This development supports the argument that technological change has been skill-biased, shifting labor demand toward employees with high levels of education. 1 $]^{1}$ A conclusion, however, that is based on indirect evidence.2. Up to now, there is little direct evidence on how skill requirements in the workplace have changed in recent decades.

A conclusive judgement of whether occupational skill requirements have changed in recent decades is only possible if measures of skill requirements in the workplace are available. Skill requirements in the workplace are difficult to measure. Most studies rely on measures of formal education or wages. Education, however, is an input factor. Firstly, it is very likely that people with equal investment in their formal education attain different levels of skills. Each education group is therefore best characterized by a distribution of skills $3^{3}$ In addition, skills that people bring to jobs in the sense of individual attributes - such as knowledge, abilities or capacities - do not necessarily coincide with the skills that are required to perform certain tasks at the workplace. $!^{4}$ Wages, on the other hand, may not reflect the "true" skill level of individuals either. This is a very likely scenario in countries with centralized wage bargaining institutions such as for example West Germany and France. It may likewise be the case in other countries owing, for example, to discrimination or segregation in the labor market.

The present study uses direct measures of occupational skill requirements based on the taskcomposition of occupations to assess whether there has been a skill upgrading in the workplace in recent decades. Labor market institutions or other factors that may distort the relationship between skills and wages (or formal education) are less likely to have an equally strong influence on the task-composition of occupations.

The empirical analysis is based on occupations at the 2-digit-level. The groups are syn-

\footnotetext{
${ }^{1}$ See for example Acemoglu (1998), Berman, Bound and Griliches (1994), Berndt, Morrison and Rosenblum (1994), Autor, Katz and Krueger (1998) and Berman, Bound and Machin (1998). Comprehensive reviews of this literature can be found in Katz and Autor (1999) and Chennells and van Reenen (1999).

${ }^{2}$ See Card and DiNardo (2002) for a critique of the skill-biased technological change hypothesis based on indirect evidence.

${ }^{3}$ The evidence presented by Katz and Murphy (1992), Levy and Murnane (1992) and Juhn, Murphy and Pierce (1993) points to the importance of distinguishing between formal education and skills in the context of wage inequality. Murnane, Willett and Levy (1995) present evidence of the growing importance of cognitive skills. The diversity of skills within demographic categories is also emphasized by Heckman and Sedlacek (1985).

${ }^{4}$ See Spenner $(1983,1990)$.
} 
thesized by aggregating individual-level data for West Germany. The data set contains four waves, launched in 1979, 1985/86, 1991/92 and in 1998/99 with 26,000 individuals on average. The data set is unique in the sense that it draws a clear picture of the task-composition of occupations, that is, employees who participated in the survey indicated what they actually do in their jobs. The occupational classifications are constant over time, so that detailed analyses of the changing skill requirement patterns within occupations can be carried out on the basis of the task descriptions.

The main findings are that occupational skill requirements have increased in recent decades, even in occupations that were the least demanding in 1979. This skill upgrading has also occurred within detailed education and age groups. A numerical assessment shows that changing occupational skill requirements account for nearly 50 percent of the educational upgrading in recent decades. Given that the analysis focuses solely on the within-occupational changes in task inputs neglecting the large shifts in the occupational distribution in employment toward more skill demanding occupations such as professionals and managers, this figure is large. In addition, the paper includes direct evidence on the role workplace computerization has had in this development. The results suggest that computer technology substitutes for workers in performing manual and cognitive routine tasks, whereas it complements workers in performing non-routine cognitive tasks. This relationship is found within occupations, within occupationeducation groups and within occupation-age groups.

The paper is organized in 6 sections. The next section discusses the related literature and introduces the task framework used in this study. Section 3 describes the data set and the variables. Section 4 presents stylized facts on occupational skill requirements, and educational and technological trends in West Germany since 1979. Section 5 econometrically investigates the relationship between IT use, occupational skill requirements and educational attainment on the basis of synthetic occupation groups. Section 6 concludes.

\section{Occupational Skill Requirements and Rising Educa- tional Supplies}

The effect of technological change on the labor demand has always been a major concern of economic research. A central theme in this discussion is whether the restructuring and reorganization of workplaces owing to technological developments leads to skill upgrading or 
skill downgrading.5 The discussion has intensified with the spread of computer technology at workplaces in recent decades. Based on the observed shifts in the earnings distribution in the U.S. in recent decades, non-neutral technological change, increasing the productivity of highly skilled employees more than that of less skilled workers, has been given particular attention. In addition, the "polarization" of the labor force has been discussed $\sqrt[6]{6}$

Empirical research has provided evidence of robust correlations between computer-based technologies and the use of highly skilled employees on various aggregation levels, strengthening the hypothesis that recent technological change has been skill-biased. These studies emphasize the higher skills now required at the workplace owing to computerization 7 In addition, the stylized fact of rising returns to education in spite of the fact that the supply of more educated workers increased supports the skill-biased technological change (SBTC) hypothesis.8 Katz and Autor (1999), Acemoglu (2002) and Chennells and van Reenen (1999) give comprehensive reviews of the literature on SBTC, covering the major studies in this field of research. Empirical studies by Falk (2001), Falk and Koebel (2001), Fitzenberger (1999) and Kaiser (2000) investigate SBTC in West Germany. The picture they present is consistent with the view that recent technological change in West Germany has also been skill-biased.

Most studies in the SBTC literature use "traditional" skill measures to assess the skill level

${ }^{5}$ A classical study is Braverman (1974), others are Spenner (1983) and Diprete (1988). Goldin and Katz (1996, 1998) provide a historical perspective on the relationship between technology and skill demand.

${ }^{6}$ See e.g. Levy and Murnane (1992).

${ }^{7}$ The oppositional view has been taken by the over-education literature that states that skill requirements did not change considerably in recent decades and that the increased deployment of highly-educated employees resulted in them holding occupations that were previously performed by employees with lower education levels. Empirical studies are, for example, Rumberger (1987), Duncan and Hoffman (1981), Sicherman (1991), AlbaRamirez (1993), Verdugo and Verdugo (1989) and Groot and Maassen van den Brink (2000). The empirical studies have been criticized for the way they operationalize over-education (see, among others, Halaby, 1994, Smith, 1986). In addition, results of recent studies that take unobserved heterogeneity into account or use instrumental variable techniques question the positive wage effects of over-education found in cross-section analyses (see e.g. Bauer, 2002). These results suggest that part of what is referred to over-education simply reflects the heterogeneity of individual abilities and skills within particular educational qualifications.

${ }^{8}$ The analysis in the present study focuses on technological change (as opposed to de-industrialization and globalization as alternative explanations for the skill upgrading in recent decades), measured by workplace computerization, because it is the only explanation that generates predictions about within-occupational task changes. De-industrialization and globalization, on the other hand, emphasize between-industry or betweenoccupation developments. In addition, SBTC is the only factor that explains why the large increase in the supply of more educated workers has not been accompanied by a decrease in the education premium in recent decades. 
of employees, such as production workers/non-production workers or blue-collar/white-collar workers $9^{9}$ These classifications use divisions according to occupational groups which are of limited usability in determining skill requirements. They document for example the structural shift toward increased deployment of white-collar work in all major sectors of industrialized countries.

The recent study by Autor, Levy and Murnane (2003), however, now offers a framework that makes it possible to analyze occupational skill requirements directly 10 The major feature of their framework is that they conceptualize work as a series of tasks, and therefore, the changing task composition of occupations in recent decades can be analyzed.

Following this framework, I use direct measures of occupational skill requirements that are based on the activities people perform on the job. These activities are classified in five skill categories: non-routine analytical tasks such as research, planning or evaluation activities; non-routine interactive tasks such as the coordination and delegation of work; routine cognitive tasks such as double-entry bookkeeping and calculating; routine manual tasks such as machine feeding or running a machine and non-routine manual tasks such as housekeeping or restoring houses.

The terms routine and non-routine characterize the relationship between the respective task measure and IT ${ }^{11}$ Both manual and cognitive routine tasks are well-defined in the sense that they are expressible in rules, which makes them easily programmable, therefore computers can perform them at economically feasible costs (Levy and Murnane, 1996). Hence, routine tasks are subject to substitution by computer capital. Non-routine tasks are not well-defined and programmable, often because they require optical recognition so that they are not expressible in rules. Therefore, at present, they cannot be accomplished by computers. However, computer capital is complementary to non-routine cognitive tasks, both analytical and interactive, in the sense that computer technology increases the productivity of employees performing those tasks. The term analytical refers to the ability of workers to think, reason and solve problems encountered at the workplace. The term interactive refers not only to communication skills -

\footnotetext{
${ }^{9}$ For example Berman, Bound and Griliches, (1994), Berndt, Morrison and Rosenblum, (1994).

${ }^{10}$ This framework sheds light on the "black box" that typically encloses studies on SBTC, as was, for example, expressed by Bresnahan (1999, p. 340): “...(skill-biased technological change) also tends to be something of a residual concept, whose operational meaning is often labor demand shift with invisible cause".

${ }^{11}$ Following Autor, Levy and Murnane (2003), the occupational production function is assumed to have a constant returns to scale Cobb-Douglas form: $Q=\left(L_{R}+C\right)^{1-\beta} L_{N}^{\beta}, \beta \in(0,1)$, where $L_{R}$ and $L_{N}$ are routine and non-routine task inputs and $C$ is computer capital, all measured in efficiency units. The exogenously declining price of computer capital is the causal force in this model.
} 
that is, the ability to communicate effectively with others through speech and writing - but also to the ability to work with others, including co-workers and customers ${ }^{12}$

The scope for substitution is thus limited to certain tasks. This limited substitution relationship (Bresnahan, 1999) between IT and occupational tasks shifts the demand for labor toward employees with higher levels of educational attainment who are presumed to have a comparative advantage in performing non-routine cognitive tasks. Autor, Levy and Murnane (2003) present a general equilibrium model that is the foundation of this informal reasoning showing how computerization (owing to the exogenous declining price of computer capital) alters the allocation of labor across different task inputs.

Although the empirical evidence suggests that technological change in West Germany has also been skill-biased in recent decades, wage trends are often considered different from developments in other countries.13 Fitzenberger (1999) and Fitzenberger et al. (2001), however, provide evidence that the wage structure in West Germany is less stable than commonly believed, even though the changes are small by international standards. Wages of employees with a medium level of education deteriorated after 1980 relative to both employees with high and low levels of education, and the relative wage position of the bottom part of the wage distribution of employees with high levels of education has slightly deteriorated over time. In addition, the wage dispersion among medium- and high-educated employees increased over time. The main difference to developments in other countries is in the group of employees with low levels of education. In contrast to the wage decreases in most other countries, their wages slightly increased and the wage dispersion within this group of workers remained stable over time. However, this group of workers experienced a sharp increase in unemployment since the 1980s. The lack of adjustment of wages of employees with low levels of education is often explained by union wages that are binding floors for low-wage earners ${ }^{14}$

\footnotetext{
${ }^{12}$ Case studies identified analytical and interactive skills as the "key" skills required by modern workplaces in industrialized countries (for example Hirschhorn, 1984, Stasz, 1997, 2001).

${ }^{13}$ The most comprehensive analyses of wage trends exists for the U.S., for example by Bound and Johnson (1992), Katz and Murphy (1992), Levy and Murnane (1992) and Juhn, Murphy and Pierce (1993). Gottschalk and Smeeding (1997) provide an international comparison of earnings and income developments since the early 1980s.

${ }^{14}$ The European unemployment problem and the U.S. inequality problem are often referred to as two sides of the same coin (Krugman, 1994, Freeman, 1995). Criticism of this hypothesis can be found for example in Nickell and Bell (1996) and Krueger and Pischke (1997). Card, Kramarz and Lemieux (1999) provide evidence for France (often considered to be similar to West Germany with respect to its labor market institutions) that is inconsistent with the "two-sides-of-the-same-coin" hypothesis.
} 
The present study is most closely related to the study by Autor, Levy and Murnane (2003) which provides the theoretical and conceptional framework for this analysis. It extends their work by focusing on within-occupational task changes. In addition, the data set used in the present study has several advantages over the Dictionary of Occupational Titles, the data set used by Autor, Levy and Murnane (2003). I provide evidence on SBTC in West Germany where previous findings are less clear than in other countries. The findings in both analyses support the argument that IT increases the demand for highly educated labor through shifting the task composition toward analytical and interactive activities for which these employees have comparative advantages.

\section{Data Set and Definition of Variables}

The analysis is based on the "Qualification and Career Survey" which is a survey of employees carried out by the German Federal Institute for Vocational Training ("Bundesinstitut für Berufsbildung (BIBB)") and the Research Institute of the Federal Employment Service ("Institut für Arbeitsmarkt- und Berufsforschung (IAB)"). It includes four cross-sections launched in 1979, 1985/86, 1991/92 and 1998/99 each covering around 30,000 individuals (men and women) 15

The level of analysis is defined by the occupational affiliation of employees. The employees are classified according to their occupation. The classification of occupational titles corresponds to that of the German Federal Employment Bureau, 1988. In the present study the 2-digit level of classification is used which includes around 80 different occupations 16 Based on the 2-digit level occupations, the micro level data of the 4 cross-sections are aggregated into occupation cells and the group means are used for the analysis. The firms employing these employees cover a wide range of industries, both services and manufacturing. Table 1 lists the 42 industries considered.

\footnotetext{
${ }^{15}$ The target population is not uniform within the four waves. Due to this changing sample design the sample used in the present study had to be restricted to West-German residents with German nationality, in other words East-German residents and non-German employees are excluded from the sample since these groups of employees were not interviewed in every wave. Moreover, the sample does not include self-employed and unemployed persons, employees with agricultural occupations and employees working in the agricultural sector. In addition, persons younger than 18 and older than 65 are excluded from the sample.

${ }^{16}$ The 2-digit level of occupational classification is used rather than the 3rd or 4th level, since it is well known that in survey data occupational affiliations are subject to measurement error issues. The potential measurement error, however, decreases the higher the level of aggregation.
} 
The data set is particularly suited to analyze changes in within occupational skill requirements since occupations in all four waves are categorized according to the 1988 classification. The constant occupational titles thus provide the reference point for the analysis. In addition, survey respondents indicated what kind of activities they perform on the job. It is very unlikely that this causes an underestimation of true changes in job content as in the Dictionary of Occupational Titles (DOT), the description of occupations often used by researchers in the U.S. for questions related to skills ${ }^{17}$ The credibility of the analysis in the present study would be impaired if the answers of survey participants with high levels of education were systematically biased toward analytical and interactive activities. I do not think, however, that this is particularly likely because survey participants only indicate whether they perform certain activities or not. They do not assign scores to the different measures. In addition, most of the analysis is performed in "first-differences". The reporting bias therefore would only pose a problem if it changed over time. As will be presented later on, the empirical results even hold within-occupation-education groups.

The most important variables for the present analysis are the measures of occupational skill requirements, the measure of technology, and the level of employees' formal education. Table 2 shows the summary statistics.

Occupational Skill Requirements: Occupational skill requirements are measured by the workers' job duties, depicted in the survey by the activities that employees have to perform at the workplace. In the light of the hypotheses, the variety of activities asked for in the survey questionnaire are pooled to five task categories. These tasks categories are: analytical tasks (such as mathematical, logical reasoning and problem-solving tasks), interactive tasks (such as interpersonal, organizational and managerial tasks), routine cognitive tasks (such as bookkeeping, time-sheet accounting and inventory control tasks), routine manual tasks and non-routine manual tasks. Table 3 illustrates the assignment of activities to the five categories. On the individual level $i$, the task measures $\left(\right.$ Task $\left._{i j t}\right)$ are defined as:

$$
\text { Task }_{i j t}=\frac{\text { number of activities in category } j \text { performed by } i \text { in cross-section } t}{\text { total number of activities in category } j \text { at time } t} * 100
$$

where

\footnotetext{
${ }^{17}$ In the DOT, experts assign scores to different indicators characterizing the occupations. It is well known that this process encourages analysts to underestimate the true changes in job content. Moreover, occupational titles in the DOT are not consistent over time (for detailed criticism see Spenner, 1983, and references cited there).
} 
$t=1979,1984 / 85,1991 / 92$ and 1998/99, and

$$
j=\left\{\begin{array}{lll}
1 & : & \text { non-routine analytic tasks } \\
2 & : & \text { non-routine interactive tasks } \\
3 & : & \text { routine cognitive tasks } \\
4 & : & \text { routine manual tasks } \\
5 & : & \text { non-routine manual tasks. }
\end{array}\right.
$$

For example, if the analytical task category includes 4 activities and employee $i$ indicates that she performs 2 of them, her analytical task measure is 0.5 .

The data set does not include information about the time spent on different activities. The most important drawback of the data set is, however, that questions concerning the activities that employees perform at the workplace changed over time. I dealt with this difficulty by reducing the activities in each category $j$ to those that are comparable over time.

IT equipment: The data set includes detailed information on the tools and machines used by the employees at the workplace. The focus in the present study is on the use of computers, terminals and electronic data processing machines. Based on these variables a dummy variable for computer use is generated indicating whether or not the employee uses one of the above devices on-the-job.

Formal Educational Attainment: The data set contains detailed information on the vocational attainment of employees. The employees are classified into three qualification groups according to their vocational education (school qualifications are not considered) 18

- People with lower levels of education, that is people with no occupational training.

- People with medium level of education, that is people with a vocational qualification who might have either completed an apprenticeship or graduated from a vocational college.

- People with high level of education, that is, people holding a degree from a university or technical college.

These variables are dummy variables, taking on the value 1 if the employee falls within the

\footnotetext{
${ }^{18}$ Most studies on West Germany use this classification rather than years of schooling because it is more appropriate to the system of vocational training. See Card (1999) for different measures of education in different institutional settings.
} 
particular education level.

Theoretically there should be 332 observations in the stacked data set (83 occupations observed in four waves). It turns out that 94.5 percent of the occupations are observed in all waves, whereas 1.5 percent of the occupations are observed only once, 1.2 percent twice and 2.8 percent are observed three times. One might wonder whether there are occupations that disappear over time and others that are newly created, in particular, as there were a number of "information technology" occupations created by the German Federal Institute for Vocational Training in recent years. The disappearance of one occupation is most arguably attributable to structural change, namely the occupation in which workers prepared minerals ("Mineralaufbereiter"). None of the occupations that appeared over time was one of the newly-founded "information technology" occupations. Overall, the occupations that were observed less than 4 times seem to be a random draw. In particular, the pattern of their appearance is clearly not driven by the question of interest.

\section{Overall Trends in Educational Supplies, Occupational Skill Requirements and the Evolution of IT at the Workplace}

As in most industrialized countries, in West Germany the labor force has witnessed a sizeable relative increase in the proportion of workers with high levels of education (see Table 44) ${ }^{19}$ The proportion of the workforce holding a university degree or a qualification from a technical college increased from about 8 percent in 1979 to more than 16 percent in 1999, whereas the proportion of employees without formal educational attainment experienced a substantial decline. However, workers with a medium level of education who either completed an apprenticeship or have a qualification from a vocational college still represent the largest proportion of the workforce 20

\footnotetext{
${ }^{19}$ The descriptive evidence is based on the individual level data.

${ }^{20}$ Spitz (2003) provides more descriptive details based on this data set. The descriptive findings are comparable to developments in other industrialized countries. For example West Germany witnessed a substantial increase in white-collar occupations and a corresponding reduction in blue-collar occupations in the last two decades of the twentieth century. The occupational group of professionals, technical workers, managers and administrators saw the highest increase as a fraction of the workforce. This group places the highest emphasis on employees with high levels of education. Formal degrees seem to have become more important in all occupational groups.
} 
Contemporaneously to this educational upgrading of the labor force, there was a considerable change in aggregate skill requirements. Table 5 shows the trends in aggregate skill inputs. The analytical task measure grew on average by 0.5 percentage points between 1979 and 1999, and the interactive task measure by 1.3 percentage points. In contrast, the requirements for routine cognitive and routine manual skills has decreased during that period with an average annual decline of 0.7 percentage points each. The trend in the requirements for non-routine manual skills was less clear. The overall period, however, suggests an increase of around 0.6 percentage points annually. Table 6 shows the aggregate trends in skill inputs for each education group separately. For each education group the analytic and interactive task measure increased over time, whereas the cognitive and manual routine task inputs declined.

Figures 1-4 illustrate this development by showing the absolute changes in aggregate skill inputs between 1979 and 1998/99. Figure 1 shows the overall trends, and Figures 2 4 4 show the development for each education group. One difference between groups is that the decline of routine cognitive task inputs and the increase in interactive and analytical task inputs was more pronounced for employees with high levels of education than for the other two groups. Employees with medium levels of education witnessed the greatest decline in routine manual activities.

This overall pattern does not suggest that high-educated employees perform more of the tasks that used to be done by medium-educated employees at the end-1990s. In contrast, the more pronounced development toward analytic and interactive activities and away from routine cognitive activities suggests that overall skill requirements were rising faster for high-educated employees than for the other groups.

The argument could be made that these overall developments reflect cohort effects, that is unobserved heterogeneity owing to, say, younger entry cohorts having better educational opportunities and therefore higher levels of analytical activities. To evaluate this possibility, Table 7 shows the trends in occupational task inputs for cohorts, defined by year of birth. The first birth cohort are individuals born before 1940, the second those born between 1940 and 1949, the third those born between 1950 and 1955 and so on. One follows one birth cohort over time by moving horizontally within the same row. One follows the same age group by moving diagonally upwards (employees born between 1956 and 1961 were between 18 and 23 years old in 1979, employees born between 1962 and 1968 were between 18 and 23 years old in However, the descriptive figures also demonstrate that each occupational category includes employees with all levels of formal education. 
1985/86). Within cohorts, changes in task inputs are attributable to age and time effects. The age effect describes how the task inputs of a given cohort changes as the cohort ages. The time effect describes how task inputs for a given cohort shift due to, for example, macroeconomic shocks. Changes in task inputs within an age group, on the other hand, are due to cohort or time effects. Cohort effects describe differences between cohorts that may, for example, be due to changes in educational opportunities ${ }^{21}$

As the figures in Table 7 show, the trend toward analytical and interactive task inputs, and away from cognitive and manual routine activities occurred both within cohorts and within age groups. The overall trends are therefore not only a reflection of cohort effects. For analytical and interactive as well as routine manual task inputs, changes within cohorts were even more pronounced than changes within age levels. Within cohorts, analytical task inputs, for example, increased by around 0.6 percentage points annually on average, whereas the annual increase within age groups was 0.5 percentage points on average.

These trends in aggregate skill requirements may result from transformations along two margins: First, changes in the occupational structure of employment, and second, changes in skill requirements within occupations ${ }^{22}$ As the results of the shift-share analysis in Table 8 shows, most of the aggregate changes in skill requirements result from within occupational changes in task measures 23 The last row, which shows the results for the entire period from 1979 to 1999, clearly illustrates this point. For example, between occupational shifts represent around 15 percent of aggregate changes in the analytical task measure whereas within occupational task changes account for around 85 percent. In the case of changes in interactive (routine manual) skill requirements the values are quite similar with around 13 (14) percent attributable to the

\footnotetext{
${ }^{21}$ It is well known that the three components - time, cohort and age effect - are not separately identifiable without additional prior assumptions. This results from the identity that links birth year c, age a and calender year t: $t=c+a$.

${ }^{22}$ Autor, Levy and Murnane (2003) provide a comprehensive analysis of the first source of variation for measuring changes in aggregate skill requirements, that is changes in the occupational structure of employees.

${ }^{23}$ The shift-share analysis decomposes the change in aggregate use of task $j$ between time $t$ and $t-1, \Delta T_{j t}=$ $T_{j t}-T_{j t-1}$, into a term reflecting the reallocation of employees between occupations and a term reflecting changes in task $j$ within occupation. The mathematical formulation is: $\Delta T_{j t}=\sum_{c}\left(\Delta E_{c t} \bar{\gamma}_{c j}\right)+\sum_{c}\left(\Delta \gamma_{c j t} \bar{E}_{c}\right)=$ $\Delta T_{j t}^{b}+\Delta T_{j t}^{w}$, where $c$ indexes occupations, $E$ denotes employment and $E_{c t}$ is the share of employment in occupation $c$ in total employment at time $t, \gamma_{c j t}$ is measure of task $j$ in occupation $c$ at time $t$. An overstrike denotes an average over time, that is $\overline{\gamma_{c j}}=\left(\gamma_{c j t}-\gamma_{c j t-1}\right) / 2$ and $\bar{E}_{c}=\left(E_{c t}-E_{c t-1}\right) / 2 . \Delta T_{j t}^{b}$ reflects the change in aggregate employment of task $j$ attributable to changes in the occupational distribution of employment and $\Delta T_{j t}^{w}$ reflects the within-occupation task changes.
} 
between shift and around 87 (86) percent to the within shift. The results for the routine cognitive task measure are even more pronounced, indicating that between-occupation shifts account for less than one percent of aggregate changes in routine cognitive skill requirements. For this task measure, it is also informative to have a look at the two subperiods 1985/86-1991/92 and 1991/92-1998/99 because between occupational results there point to slight increases in the requirements for routine cognitive skills, a pattern that has been counteracted by the within occupational task shifts. The overall result of this table of predominantly within occupational task shifts is largely in favor of technological developments rather than changes in final demand as the potential cause for changing skill requirements.

One important argument in this study is that the changes in the task composition of occupations toward analytical and interactive activities induced labor demand shifts toward employees with high levels of education who are viewed as having comparative advantages in performing non-routine cognitive tasks. Table 6 shows that the analytical and interactive task inputs are the highest for employees with high levels of education in each wave. Table 9 summarizes this result, by showing task means by education group. The descriptive evidence thus confirms the view that the higher the educational attainment, the higher the measures in analytical and interactive tasks. In contrast, the figures indicate that employees with low levels of education are mainly occupied with routine cognitive, routine manual and non-routine manual tasks. Employees with medium levels of education have relatively high measures for all five task categories, but most interestingly, the value of their task measures for routine manual and routine cognitive activities are even higher than those for employees with low levels of education.

The educational upgrading and the changes in occupational skill requirements took place at the same time as information technology began to spread at the workplace. Whereas at the beginning of the IT revolution mainframe computers dominated the data-processing units of large firms, personal computers began to spread to business users from the late 1970s onwards. Owing to the steady fall in prices, this spread has become more pronounced. Table 10 shows the percentage of computer users at work. The table shows that within twenty years, more than half of the workforce has come to use computers at work. ${ }^{24}$ Between 1979 and 1999, the spread of computers increased on average by more than 40 percent per annum. Table 10 also shows that the level of computer use increased with the educational attainment of employees. In 1979,

\footnotetext{
${ }^{24}$ The figures on computer penetration at the workplace are similar to those reported for other countries for example in Card, Kramarz and Lemieux (1999).
} 
more than 10 percent of employees with high levels of education already used a computer at the workplace compared to less than 4 percent of employees with low levels of education and around 6 percent of employees with medium levels of education. This proportion had increased to more than $80(30,55)$ percent of employees with high (low, medium) levels of education in 1999. However, it is worth noting that, with an increase of around 45 percent per annum, the pace of computer diffusion was most pronounced among employees with low levels of education between 1979 and 1999 (compared to around 42 percent per annum for employees with medium levels of education and 30 percent for employees with high levels of education).

As Table 11 shows, computer adoption has been quite different for different occupational groups. It has been particularly pronounced in professional, technical, managerial, administrative and clerical occupations. The spread of computer capital has been much broader among clerical occupations than among sales occupations. This may indicate the division of office work into back and front office functions, as for example Bresnahan (1999) pointed out, with employees in the back office (clerks) being occupied with routine cognitive and routine manual tasks such as data-entry and data-processing, and employees in the front office (sales personnel) spending most of their time serving customers and clients. In contrast to the wide spread of computers in most white-collar bureaucracies, operatives and crafts people witnessed a much slower penetration rate of IT at the workplace.

The descriptive evidence shows that educational upgrading, increased demand for analytical and interactive activities and the spread of computer technologies evolved together in recent decades. This is consistent with the argument that IT increases the demand for employees with high levels of education through shifting the task composition toward analytical and interactive activities.

\section{Skill Requirements, Education and Technology in the Workplace}

\subsection{Technological Change and Changes in Occupational Skill Re- quirements}

Based on the model by Autor, Levy and Murnane (2003) outlined in Section 2, there are two empirically testable hypotheses: (1) that IT substitutes for routine manual and routine cognitive activities, and (2) that IT is complementary to analytic and interactive activities. The 
framework emphasizes that the causal force by which IT affects skill demand is the declining price of IT. As the price of IT falls steadily, these two mechanisms have raised relative demand for employees with high levels of education who are assumed to have a comparative advantage in performing analytical and interactive activities.

The analysis that follows will investigate this substitution and complementarity hypothesis. Because there are no hypotheses on the relationship between IT and changes in non-routine manual task inputs derived from this theoretical model, I do not analyze this relationship in the following sections.

Table 12, Panel A, shows the first-difference relationship between workplace computerization and changes in occupational skill requirements. Each column represents a separate OLS regression of the annual changes in occupational task measures on the annual changes in occupational computer use. Annual changes are estimated between successive waves, that is between 1979 and $1985 / 86$, between $1985 / 86$ and $1991 / 92$ as well as between 1991/92 and 1998/99. The regressions are based on the stacked data set. They are performed including time dummies for 1985/86-1991/92 and 1991/92-1998/99 capturing the trend in within occupational tasks changes for the corresponding time period relative to the base period 1979-1985/86.

The results show that occupations that saw greater increases in computerization witnessed significantly larger increases in analytical and interactive task requirements, whereas they witnessed greater declines in routine manual and routine cognitive task requirements. The coefficients are not only statistically significant but also economically large. For example, they indicate that 50 percent of changes in analytical task inputs were accounted for by computerization 25 Similar calculations show that 47 percent of changes in interactive task inputs are accounted for by computerization and it explains 90 percent of the decline in routine cognitive skill requirements. In the case of routine manual task inputs, computerization more than fully accounts for the observed task changes.

The time dummies show that, conditional on workplace computerization, the trend change in analytical skill requirements was negative in both periods 1985/86-1991/92 and 1991/921998/99 relative to the base period of 1979-1985/86 indicating that computerization more than fully accounts for the trend toward analytical task inputs in these later periods. In contrast, the trend change toward interactive skill inputs accelerated with time even after conditioning

\footnotetext{
${ }^{25}$ At the bottom of Table 12 , the unconditional (weighted) means of the dependent variables are shown. The figures indicate an average annual increase in the analytical task measure of 0.425 percentage points. Using the coefficient of 0.086 and the mean value of changes of computer utilization of 2.465 percentage points, this implies that around 50 percent of changes in analytical tasks is accounted for by changes in IT usage.
} 
on computerization. In the routine tasks equations, the coefficients of the time dummies are mostly insignificant, except for a large positive trend in 1991/92-1998/99 in routine cognitive skills.

Panel B shows the result when the lagged annual changes in computer use within occupation cell is used as regressor instead of contemporaneous changes in workplace computerization. The results of the lagged specification confirm the previous findings reported in Panel A, with the exception of the analytical task equation that now has an insignificant coefficient. The coefficient in the routine cognitive equation even increases in absolute terms suggesting that there might be a time lag until the full impact of computerization is reflected in occupational skill requirements. Unreported regressions in which the lagged proportion of computer users are included as an alternative measure confirm these results. These results of the lagged specification favor the argument derived from the theory that workplace computerization, brought about by the declining prices of IT-equipment, induced task shifts and not vice versa.

Table 13, Panel A, shows the result of a richer specification that tests whether changes in occupational skill requirements are implicitly captured by changes in the educational structure or changes in the gender structure of occupations. Neither of the additional regressors alters the qualitative relationship between computerization and changes in occupational skill requirements found in the bivariate regressions, and even the size of the coefficients are relatively insensitive to the additional controls. Only in the analytical task equation, the coefficient drops slightly more than ten percent. Changes in the proportion of employees with high levels of education turn out to play a significant role with respect to changes in interactive and analytical skill requirements, whereas changes in the proportion of employees with medium levels of education appear to be bad predictors of changes in occupational task inputs. Changes in the proportion of female employees are even negatively related to changes in analytical skill requirements, hence they fail to provide an alternative explanation for increasing analytical skill requirements. However, occupations with greater increases in the proportion of female employees witnessed relatively larger declines in routine cognitive skill requirements. ${ }^{26}$

Panel B shows the results when lagged annual changes are included as regressors in the analysis instead of contemporaneous changes. The results for the relationship between com-

\footnotetext{
${ }^{26} \mathrm{I}$ also performed regressions that include changes in work-based learning (average years of work experience and average years of tenure with current employer) into the analysis. Both measures of work-based learning were not significantly related to changes in occupational task inputs. The results are not reported because the inclusion of these additional variables did not alter the main findings reported in Table 13 .
} 
puterization and changes in occupational skill requirements are similar to those reported in Table 12, Panel B. For changes in analytical skill requirements, contemporaneous changes in all variables seem to pick up more of the relevant information. Unlike the variable for workplace computerization, a comparison of the results for education and gender variables with those in Panel A reveals, however, that they are not insensitive to the change in specification.

Table 14 shows the results referring to the relationship between workplace computerization and changes in occupational skill requirements for each education group separately. For each occupation-education group, the results are consistent with the hypotheses of a complementary relationship between computer technology and analytical and interactive activities, and a substitutive relationship between computer technology and manual and cognitive routine tasks. However, for part of the coefficients, the level of significance drops considerably. This is particularly pronounced for the group of employees with a high level of education 27 There are two potential explanations for this finding. First, that changes in the task composition owing to workplace computerization are less pronounced for employees with high levels of education because their values of the task measures were already at the extreme of the distribution in 1979. Second, that for this group of workers the analysis might be particularly impaired by the fact that the task measures do not include information about the time spent with the different activities. This time dimension might be more important for employees who always had a high number of activities that they perform. In line with these arguments, the results for employees with a low level of education are the clearest with respect to the magnitude and significance of the coefficients. For this group of employees, workplace computerization has had a large effect on the occupational production function.

The last dimension analyzed in the present study are cohorts. If younger labor market entry cohorts have both higher levels of, for example, analytical abilities and higher levels of computer use, the above findings may be the result of a spurious correlation. Table 15 shows the results of the above regressions for each birth cohort separately ${ }^{28}$

The results suggest a complementary relationship between computer technologies and analytical and interactive activities and a substitutive relationship between computer technologies and cognitive and manual routine activities within each occupation-cohort group. Therefore, the previous findings do not seem to be a mere reflection of cohort effects.

\footnotetext{
${ }^{27}$ Autor, Levy and Murnane (2003) report similar findings on the industry level.

${ }^{28}$ Only cohorts that are observed over the entire period 1979-1998/99 are shown.
} 


\subsection{Changes in Skill Requirements and Educational Upgrading}

\subsubsection{Contribution of Changes in Occupational Skill Requirements to the Educa- tional Upgrading}

In this section, I calculate the potential contribution of shifts in occupation skill requirements to shifts in employment of labor with high levels of education and with medium levels of education. This is done by firstly estimating an equation of educational requirements as a function of task inputs, an exercise that aims to translate occupational skill requirements into education-equivalents. The regression equation is:

$$
E D_{i c t}=\alpha_{0 i t}+\sum_{j=1}^{4} S_{j c t} \alpha_{i j t}+v_{i c t}
$$

$t=1979,1985 / 86,1991 / 92,1998 / 99$

$j=1, \ldots, 4$.

$i=$ high or medium

$c=$ occupation

$$
j=\left\{\begin{array}{rll}
1 & : & \text { non-routine analytic task measure } \\
2 & : & \text { non-routine interactive task measure } \\
3 & : & \text { routine cognitive task measure } \\
4 & : & \text { routine manual task measure }
\end{array}\right.
$$

where $E D_{i c t}$ is the proportion of employees with education level $i$ in occupation $c$ at time $t$. $S_{j c t}$ is the measure of task $j$ in occupation $c$ at time $t$. The $\alpha_{i j t}$ s estimated in the regression provide an estimate of the demand for employees with high (medium) level of education as a function of occupation skill requirements. This is what Autor, Levy and Murnane (2003) call a "fixed coefficient" model because, by assuming the $\alpha_{i j t}$ s to be constant over the period, it neglects the impact of task prices on task demand. If the prices of analytical and interactive task inputs relative to routine task inputs has risen, for example, this model will lead to an underestimation of shifts toward analytical and interactive tasks and thus to an underestimation of the educational upgrading of the workforce. 
The estimated coefficients $\alpha_{i j t}$ of equation (2) are used to predict changes in the demand for employees with high and medium levels of education.

$$
\Delta \hat{D}_{i c \tau}=\sum_{j=1}^{4} \Delta S_{j c \tau} \hat{\alpha}_{i j(t-1)}
$$

$\tau=t-(t-1)$ with $\mathrm{t}=1979,1985 / 86,1991 / 92,1998 / 99$.

The results of estimating equation (2) separately for employees with high and medium levels of education and for each wave are shown in Table 16. Panel A presents the results for the proportion of employees with high levels of eduction. In each wave, the results indicate a strong (and mostly highly significant) positive relationship between analytical and interactive task inputs and the proportion of employees with high education levels. In 1979, for example, a one percentage point increase in analytical skill requirements results in a 1.3 percentage point increase in the demand for employees with high level of education. The results for the routine cognitive and routine manual task measures are also in line with the a priori expectations, although the coefficients are often insignificant.

Panel B shows the results for the proportion of employees with medium level of education. With most of the coefficients being insignificant, the results are less clear-cut than those for employees with high levels of education. The overall picture suggests, however, a positive relationship between routine cognitive and routine manual task inputs and the proportion of employees with medium levels of education, whereas the relationship with respect to analytical and interactive task inputs is negative.

Panel A of Table 17 shows the observed annual changes in the proportion of employees with high and medium level of education for the subperiods 1979-85/86, 1985/86-91/92, 1991/9298/99 and for 1979-1998/99. The pace of educational upgrading was relatively stable since the mid-1980s with average annual changes of 0.5 percentage points. Between 1979 and 1998/99 the proportion of employees with high level of education grew on average by 0.4 percentage points per annum. The proportion of employees with medium levels of education decreased considerably between 1979 and 1985/86, increased between 1985/86 and 1991/92 and declined again in the 1990s. Over the whole period, however, this resulted in an average annual decrease of 0.1 percentage points.

In what follows, I will largely concentrate the discussion of results on the whole period 19791998/99, although the results for the different subperiods are mostly comparable. However, macroeconomic shocks might affect the outcomes in these subperiods such as for example the 
recessions that West Germany experienced at the beginning of the 1980s and around 1992/1993, and also the unification boom just at the beginning of the 1990s might be important with this respect.

Two different measures of $\Delta S_{j c \tau}$ are used to calculate $\Delta E D_{i c \tau}$ of equation (3): first, observed changes in occupation skill requirements and second, predicted changes in occupation skill requirements implied by computerization. In the calculations that follow, I will only use the $\alpha_{i j}$ s of the year 1979. The relationship between task inputs and education in 1979 is closest to the pre-computer era. Desktop computing, for example, only became widespread in the 1980s and 1990s.

Panel B shows the observed changes in occupation skill requirements. Requirements for analytical and interactive skills within occupation grew between 1979 and 1998/99, with the pace of increases in interactive inputs accelerating steadily. The figures show a steady decline in occupation requirements for routine cognitive skills and also for routine manual skills.

Inserting the observed changes in occupation skill requirements, together with the $\hat{\alpha} \mathrm{s}$ of Table 16-first column, into equation (3) shows that the observed changes in occupational skill requirements account for nearly 50 percent of the changes in the proportion of employees with high level of education between 1979 and 1998/99 (Panel C). With respect to the observed changes in the proportion of employees with medium levels of education, observed changes in the occupational skill requirements even accounted for around 65 percent of observed changes.

Panel D shows the results of the predicted changes in occupation skill requirements that are implied by computerization. These figures are based on the regression specification shown in Table 12, Panel A. The overall picture complies with the figures in Table 17, Panel B. Computerization implies an increase in occupational requirements for analytical and interactive tasks and a reduction in routine manual and routine cognitive tasks. The deviation between observed changes in skill requirements and the predictions implied by computerization is most pronounced in the nineties, where the predicted figures show a shift toward routine cognitive tasks.

Panel E shows the proportion of observed changes in the share of employees with high and medium level of education explained by predicted changes in occupation skill requirements implied by computerization. Between 1979 and 1998/99, occupational task changes induced by computerization account for more than 40 percent of the overall skill upgrading. This figures reaches with 47 (32) percent its height (low) in the first and last (second) subperiod. With respect to changes in the proportion of employees with medium levels of education, task shifts induced by computerization account for nearly 50 percent of the observed pattern of 
employment.

Given that these changes in skill requirements are only those within occupations, these figures show the substantial economic impact of changes in the skill requirements on the educational upgrading of the workforce. In addition, the analysis shows the role of workplace computerization in reshaping the occupational production process. Changes in occupational skill requirements implied by computerization account for 85 percent of the proportion of educational upgrading that is explained by observed task shifts.

\subsubsection{Changes in Occupational Skill Requirements Using a Scalar Index}

The question that has been neglected in the analysis so far is, whether there has been a polarization of work in recent decades ${ }^{29}$ The argument is that the substitution of, for example, routine cognitive tasks by computer technologies effects occupations such as bookkeepers and bank employees that are traditionally held by employees with medium levels of education. Non-routine manual activities, on the other hand, that, at present, cannot be accomplished by computers, are frequent in occupations that are often held by employees with low levels of education such as waiters.

In order to investigate this question further I constructed a scalar index of occupational skill requirements. This skill index is the predicted value derived from the regression presented in Table 16, Panel A, for 1979. Based on the 1979 value of this skill index, I classified the occupations into four groups. Occupations whose value of the skill index in 1979 was in the lowest quartile are the first group, occupations in the second quartile are the second group and so on. I first analyze how skill requirements have changed within the four occupation groups, then I examine how the employment distribution has changed among these groups in order to investigate the question of "polarization".

Table 18 shows the evolution of the skill index for each occupation group. In addition, the table also includes the proportion of employees with low, medium and high educational attainment within this occupation groups. As can be seen, the value of the skill index increased within each group of occupations. The increase was particularly pronounced for the group of occupations whose 1979 value was in the first quartile and those whose 1979 value was in the fourth quartile.

Figures 5.8 show the absolute changes in the skill index (relative to the 1979 values) within each of the four groups. In addition, the absolute changes in the proportion of employees with

\footnotetext{
${ }^{29}$ See, for example, Levy and Murnane (1992) and Goos and Manning (2003).
} 
high, medium and low levels of education are included. Figure 5 shows the developments for occupations that were the least demanding in terms of the value of the skill index in 1979. For this group of occupations the skill index rose more than 50 percentage points. This development was accompanied by an increase in the proportion of employees with high and medium levels of education, whereas the proportion of low educated employees declined over time. Figure 6 shows the pattern for the group of occupations whose 1979 value of the skill index was in the second quartile. The development in this group of occupations can be characterized by a shift toward employees with medium levels of education and away from employees with low education since 1985/86. The proportion of employees with high levels of education, however, remained stable. This pattern of development was quite similar for occupations which are grouped into the third category, although the development was much less pronounced. As Figure 8 shows, occupations with the highest skill index in 1979, witnessed both a large increase in skill requirements and a pronounced educational upgrading. For this group of occupations the proportion of both employees with low and medium levels of education declined.

Based on these tables and figures it is difficult to assess whether the educational upgrading within each occupation group was "appropriate" giving the evolution of skill requirements, but the steep increase in occupational skill requirements even in occupation groups that were the least skill demanding in 1979 suggest that medium or high educated employees who moved into these groups of occupations are now performing tasks that are different from those that have been performed by low educated employees.

The question of whether there has been a "hollowing out" of middle-class occupations concerns the employment trends within these groups of occupations. Therefore, I calculated the distribution of employment among the different groups of occupations over time. Table 19 shows the employment shares for each occupation group over time, Figure 9 shows the absolute employment changes. Employment in occupations of the second group has always been the smallest. However, the decline in their employment share was not more pronounced than for occupations in the first group. As Figure 9 shows, employment in both the first and second occupation group has declined, whereas occupations in the third and fourth quartile have experienced a relative increase. These figures thus do not indicate that there was a "hollowing out" of middle-class occupations, at least not in terms of occupational skill requirements. They rather suggest a monotone shift toward more skill intensive occupations. 


\section{Conclusions}

Are skill requirements in the workplace rising? The analysis in the present paper answers this question, first, by investigating whether skill requirements within formally identical occupations changed between 1979 and 1999, and second, by exploring the role of workplace computerization in this development.

The results suggest that formally identical occupations today involve greater complexity than two decades ago. In recent decades, occupations have experienced a shift toward analytical and interactive activities, and away from cognitive and manual routine tasks. This development was ubiquitous in the sense that it occurred within occupations, within occupation-education groups and within occupation-age groups. Even those occupations that were the least demanding in 1979 now require a greater degree of complexity. In addition, the results indicate that the diffusion of information technologies in the workplace has intensified these changes in the occupational production function. This comes from the fact that IT substitutes for workers in performing manual and cognitive routine tasks, but complements workers in performing analytical and interactive activities.

The overall result that occupations today require more skills emphasizes the importance of education and training in order to enable employees to cope with the challenges brought about by the changing task composition of occupations. It draws a particularly pessimistic perspective for the labor market prospects of employees with low levels of education. This group of employees has experienced the least favorable labor market development in recent decades. It has experienced either a decrease in wages or has been crowded out of the labor market in most industrialized countries. As the skill level of employees with low levels of education no longer meets the minimum occupational skill requirements, they become increasingly marginalized. 


\section{References}

Acemoglu, D. (1998). Why Do New Technologies Complement Skills? Directed Technical Change and Wage Inequality, Quarterly Journal of Economics 113(4): 1055-1089.

Acemoglu, D. (2002). Technical Change, Inequality, and the Labor Market, Journal of Economic Literature 40: 7-72.

Alba-Ramirez, A. (1993). Mismatch in the Spanish Labor Market. Overeducation?, Journal of Human Resources 28(2): 259-278.

Autor, D., Katz, L. and Krueger, A. (1998). Computing Inequality: Have Computers Changed the Labor Market?, Quarterly Journal of Economics 113(4): 1169-1213.

Autor, D., Levy, F. and Murnane, R. (2003). The Skill Content of Recent Technological Change: An Empirical Exploration, Quarterly Journal of Economics 118(4): 1279-1333.

Bauer, T. (2002). Educational Mismatch and Wages in Germany, Economics of Education Review 21(3): 221-229.

Berman, E., Bound, J. and Griliches, Z. (1994). Changes in the Demand for Skilled Labor Within U.S. Manufacturing: Evidence from the Annual Survey of Manufactures, Quarterly Journal of Economics 109: 367-397.

Berman, E., Bound, J. and Machin, S. (1998). Implication of Skill-Biased Technological Change: International Evidence, Quarterly Journal of Economics 113: 1245-1279.

Berndt, E., Morrison, C. and Rosenblum, L. (1994). High-Tech Capital Formation and Labor Composition in U.S. Manufacturing Industries: An Exploratory Analysis, Journal of Econometrics 65(1): 9-43.

Bound, J. and Johnson, G. (1992). Changes in the Structure of Wages in the 1980's: An Evaluation of Alternative Explanations, American Economic Review 82(3): 371-392.

Braverman, H. (1974). Labor and Monopoly Capital, Monthly Review Press, New York and London.

Bresnahan, T. (1999). Computerisation and Wage Dispersion: An Analytical Reinterpretation, Economic Journal 109: F390-F415.

Card, D. (1999). The Causal Effect of Education on Earnings, in O. Ashenfelter and D. Card (eds), Handbook of Labor Economics, Elsevier Science, Amsterdam, pp. 1801-1863.

Card, D. and DiNardo, J. (2002). Skill Biased Technological Change and Rising Wage Inequality: Some Problems and Puzzels, Working Paper 8769, NBER. 
Card, D., Kramarz, F. and Lemieux, T. (1999). Changes in the Relative Structure of Wages and Employment: A Comparison of the United States, Canada, and France, Canadian Journal of Economics 32(4): 843-877.

Chennells, L. and van Reenen, J. (1999). Has Technology Hurt Less Skilled Workers?, Working Paper Series W99/27, Institute for Fiscal Studies.

Diprete, T. (1988). The Upgrading and Downgrading of Occupations: Status Redefinition vs. Deskilling as Alternative Theories of Changes, Social Forces 66(6): 725-746.

Duncan, G. and Hoffman, S. (1981). The Incidence and Wage Effects of Overeducation, Economics of Education Review 1(1): 75-86.

Falk, M. (2001). Diffusion of Information Technology, Internet Use and the Demand for Heterogenous Labor, Discussion Paper 01-48, ZEW Mannheim.

Falk, M. and Koebel, B. (2001). A Dynamic Heterogeneous Labor Demand Model for German Manufacturing, Applied Economics 33(3): 330-348.

Fitzenberger, B. (1999). Wages and Employment Across Skill Groups, Vol. 6 of ZEW economic studies, Physica-Verlag, Heidelberg and New York.

Fitzenberger, B., Hujer, R., McCurdy, T. and Schnabel, R. (2001). Testing for Uniform Wage Trends in West-Germany: A Cohort Analysis Using Quantile Regressions for Censored Data, Empirical Economics 26: 41-86.

Freeman, R. (1995). Are Your Wages Set in Beijing?, Journal of Economic Perspectives 9: 1532.

Goldin, C. and Katz, L. (1996). Technology, Skill, and the Wage Structure: Insights from the Past, American Economic Review 86: 252-257.

Goldin, C. and Katz, L. (1998). The Origins of Technology-Skill Complementarity, Quarterly Journal of Economics 113: 693-732.

Goos, M. and Manning, A. (2003). Lousy and Lovely Jobs: The Rising Polarization of Work in Britain, Technical report, Center for Economic Performance, LSE.

Gottschalk, P. and Smeeding, T. (1997). Cross-National Comparisons of Earnings and Income Inequality, Journal of Economic Literature 35(2): 633-687.

Groot, W. and Maassen van den Brink, H. (2000). Overeducation in the Labor Market: A Meta-Analysis, Economics of Education Review 19: 149-158.

Halaby, C. (1994). Overeducation and Skill Mismatch, Sociology of Education 67(1): 47-59. 
Heckman, J. and Sedlacek, G. (1985). Heterogeneity, Aggregation, and Market Wage Functions: An Empirical Model of Self-Selection in the Labor Market, Journal of Political Economy 93(6): 1077-1125.

Hirschhorn, L. (1984). Beyond Mechanization: Work and Technology in a Postindustrial Age, MIT Press, Cambridge, Massachusetts.

Juhn, C., Murphy, K. and Pierce, B. (1993). Wage Inequality and the Rise in Returns to Skill, Journal of Political Economy 101(3): 410-442.

Kaiser, U. (2000). New Technologies and the Demand for Heterogeneous Labor: Firm-Level Evidence for the German Business-Related Service Sector, Economics of Innovation and New Technology 9(5): 465-484.

Katz, L. and Autor, D. (1999). Changes in the Wage Structure and Earnings Inequality, in O. Ashenfelter and D. Card (eds), Handbook of Labor Economics, Elsevier Science B.V., pp. 1463-1555.

Katz, L. F. and Murphy, K. M. (1992). Changes in Relative Wages, 1963-1987: Supply and Demand Factors, Quarterly Journal of Economics 107(1): 35-78.

Krueger, A. and Pischke, J. (1997). Observations and Conjectures on the U.S. Employment Miracle, Working Paper 6146, NBER.

Krugman, P. (1994). Past and Perspective Causes of High Unemployment, in Federal Reserve Bank of Kansas City (ed.), Reducing Unemployment: Current Issues and Policy Options, pp. $68-81$.

Levy, F. and Murnane, R. (1992). U.S. Earnings Levels and Earnings Inequality: A Review of Recent Trends and Proposed Explanations, Journal of Economic Literature 30: 1333-1381.

Levy, F. and Murnane, R. (1996). With What Skills Are Computers a Complement, American Economic Review 86(2): 258-262.

Murnane, R., Willett, J. and Levy, F. (1995). The Growing Importance of Cognitive Skills in Wage Determination, Review of Economics and Statistics 77: 251-266.

Nickell, S. and Bell, B. (1996). Changes in the Distribution of Wages and Unemployment in OECD Countries, American Economic Review 86: 302-308.

Rumberger, R. (1987). The Impact of Surplus Schooling on Productivity and Earnings, Journal of Human Resources 22(1): 24-50.

Sicherman, N. (1991). "Overeducation" in the Labor Market, Journal of Labor Economics 9(2): 101-122. 
Smith, H. (1986). Overeducation and Underemployment: An Agnostic Review, Sociology of Education 59(2): 85-99.

Spenner, K. (1983). Deciphering Prometheus: Temporal Change in the Skill Level of Work, American Sociological Review 48(6): 824-837.

Spenner, K. (1990). Skill: Meaning, Methods, and Measures, Work and Occupations 17(4): 399 421.

Spitz, A. (2003). IT Capital, Job Content and Educational Attainment, Discussion Paper 03-04, ZEW Mannheim.

Stasz, C. (1997). Do Employers Need the Skills They Want? Evidence from Technical Work, Journal of Education and Work 10(3): 205-223.

Stasz, C. (2001). Assessing Skills for Work: Two Perspectives, Oxford Economic Papers 3: 385405.

Verdugo, R. and Verdugo, N. (1989). The Impact of Surplus Schooling on Earnings: Some Additional Findings, Journal of Human Resources 24(4): 629-643. 
Table 1: Industry Classification

\begin{tabular}{ll}
\hline \hline Manufacturing incl. construction and mining \\
10 & Mining \\
11 & Chemical Industry, Rubber and Synthetic Material \\
12 & Stone and Clay, Glass and Ceramics \\
13 & Iron and Steel Production \\
14 & Steel and Light Metal, Tracked Vehicles \\
15 & Machine Construction \\
16 & Car Industry \\
17 & Shipbuilding, Aircraft and Aerospace Industry \\
18 & Office and Data-Processing Machines \\
19 & Electrical Engineering \\
20 & Precision and Optical Instruments \\
21 & Musical Instruments, Toys, and Jewellery \\
22 & Construction \\
23 & Wood Processing \\
24 & Cellulose and Paper Industry \\
25 & Printing \\
26 & Leather and Shoe Industry \\
27 & Textile Industry \\
28 & Food, Beverages and Tobacco \\
Services & Laundry and Dry Cleaning \\
29 & Hairdressing \\
30 & Trade \\
52 & Transport Services (including Carriage, \\
51 & Travel Agency, Warehouse) \\
53 & Credit Institutions \\
54 & Insurance Companies \\
55 & Catering and Hotels \\
57 & Health and Veterinary \\
61 & Radio, TV, Publishing House, Art, Theater, Museum \\
\hline \hline
\end{tabular}


Table 2: Summary Statistics on the Occupation Level (weighted by the number of individuals within occupation group)

\begin{tabular}{lcccc}
\hline Variable & Mean & Std. Dev. & Minimum & Maximum \\
\hline \hline average value of... & & & & \\
$\quad$ analytic task measure & 9.419 & 8.416 & 0.000 & 50.000 \\
$\quad$ interactive task measure & 16.257 & 13.434 & 0.000 & 66.667 \\
$\quad$ routine cognitive task measure & 29.317 & 22.974 & 0.000 & 100.000 \\
$\quad$ routine manual task measure & 24.542 & 20.919 & 0.000 & 100.000 \\
$\quad$ non-routine manual task measure & 19.643 & 19.176 & 0.000 & 100.000 \\
proportion of ... & & & & \\
$\quad$ computer users & 28.348 & 29.921 & 0.000 & 100.000 \\
$\quad$ employees with high education & 11.126 & 23.333 & 0.000 & 100.000 \\
$\quad$ employees with medium education & 70.633 & 23.595 & 0.000 & 100.000 \\
employees with low education & 18.242 & 16.375 & 0.000 & 100.000 \\
female employees & 38.710 & 29.417 & 0.000 & 100.000 \\
annualized changes in... & & & & \\
analytic task measure & 0.425 & 0.760 & -5.556 & 4.218 \\
$\quad$ interactive task measure & 0.980 & 1.019 & -4.167 & 6.111 \\
routine cognitive task measure & -0.849 & 3.238 & -12.245 & 14.286 \\
routine manual task measure & -0.504 & 3.301 & -10.030 & 10.829 \\
non-routine manual task measure & 0.607 & 2.429 & -8.477 & 11.136 \\
computer use & 2.465 & 1.834 & -8.333 & 12.500 \\
the prop. of empl. w/ high educ. & 0.266 & 1.258 & -10.417 & 16.667 \\
the prop. of empl. w/ medium educ. & -0.049 & 1.409 & -11.310 & 8.333 \\
the prop. of empl. w/ low educ. & -0.363 & 1.326 & -11.111 & 11.012 \\
the prop. of female empl. & 0.264 & 0.725 & -11.111 & 9.028 \\
\hline \hline
\end{tabular}


Table 3: Assignment of Activities

\begin{tabular}{ll}
\hline \hline Classification & Tasks \\
\hline \hline non-routine analytic & research, evaluation and planning, \\
& making plans, constructions, designing, sketching \\
& working out rules/prescriptions \\
& using and interpreting rules \\
\hline non-routine interactive & negotiating, lobbying, coordinating, organizing \\
& teaching or training \\
& selling, buying, advising customers, advertising \\
& entertaining or presenting \\
& employ or manage personnel \\
& calculating, bookkeeping \\
& correcting of texts/data \\
& measuring of length/weight/temperature \\
\hline routine cognitive & operating or controlling machines \\
& equip machines \\
\hline routine manual & repairing or renovation houses/apartments/machines/vehicles \\
& restoring of art/monuments \\
& serving or accomodating \\
\hline non-routine manual
\end{tabular}

Table 4: Proportion of Different Educational Groups in Employment

\begin{tabular}{lcccc}
\hline \hline \multicolumn{5}{c}{ Sample } \\
& 1979 & $1985 / 86$ & $1991 / 92$ & $1998 / 99$ \\
\hline High Level of Education & 8.18 & 8.85 & 13.30 & 16.48 \\
Medium Level of Education & 72.38 & 68.33 & 71.28 & 70.57 \\
Low Level of Education & 21.84 & 22.81 & 15.42 & 12.95 \\
\hline \hline
\end{tabular}

The sample includes workers aged 18-65 with residence in West Germany and of German nationality (89687 observations). 
Table 5: Trends in Aggregate Skill Inputs

\begin{tabular}{lccccc}
\hline \hline & $\begin{array}{c}\text { analytic } \\
\text { skills }\end{array}$ & $\begin{array}{c}\text { interactive } \\
\text { skills }\end{array}$ & $\begin{array}{c}\text { routine } \\
\text { cognitive }\end{array}$ & $\begin{array}{c}\text { routine } \\
\text { manual }\end{array}$ & $\begin{array}{c}\text { non-routine } \\
\text { manual skills }\end{array}$ \\
\hline 1979 & 4.42 & 8.47 & 36.86 & 30.88 & 14.19 \\
$1985 / 86$ & 9.71 & 10.47 & 31.81 & 26.18 & 19.90 \\
$1991 / 92$ & 10.98 & 16.55 & 26.97 & 23.48 & 19.78 \\
$1998 / 99$ & 13.93 & 33.81 & 22.11 & 17.19 & 26.04 \\
\hline \hline
\end{tabular}

The sample includes workers aged 18-65 with residence in West Germany and of German nationality (89603 observations).

Table 6: Trends in Aggregate Skill Inputs by Education

\begin{tabular}{lccccc}
\hline \hline & $\begin{array}{c}\text { analytic } \\
\text { skills }\end{array}$ & $\begin{array}{c}\text { interactive } \\
\text { skills }\end{array}$ & $\begin{array}{c}\text { routine } \\
\text { cognitive }\end{array}$ & $\begin{array}{c}\text { routine } \\
\text { manual }\end{array}$ & $\begin{array}{c}\text { non-routine } \\
\text { manual skills }\end{array}$ \\
\hline \multicolumn{5}{c}{ Employees with High Level of Education } \\
\hline 1979 & 15.45 & 20.10 & 42.51 & 15.59 & 4.10 \\
$1985 / 86$ & 21.40 & 18.76 & 45.74 & 9.30 & 4.46 \\
$1991 / 92$ & 26.29 & 35.23 & 34.33 & 8.70 & 5.75 \\
$1998 / 99$ & 24.62 & 48.40 & 11.44 & 7.77 & 2.41 \\
\hline \multicolumn{5}{c}{ Employees with Medium Level of Education } \\
\hline 1979 & 4.16 & 8.63 & 39.15 & 33.40 & 16.18 \\
$1985 / 86$ & 9.29 & 10.41 & 33.31 & 28.85 & 24.18 \\
$1991 / 92$ & 9.39 & 14.99 & 28.22 & 26.27 & 23.73 \\
$1998 / 99$ & 11.88 & 28.34 & 24.08 & 19.44 & 26.80 \\
\hline
\end{tabular}

Employees with Low Level of Education

\begin{tabular}{llclll}
\hline 1979 & 2.78 & 4.80 & 27.47 & 26.50 & 10.11 \\
$1985 / 86$ & 6.29 & 7.34 & 21.58 & 24.74 & 13.27 \\
$1991 / 92$ & 4.94 & 7.47 & 20.42 & 23.37 & 13.73 \\
$1998 / 99$ & 6.92 & 14.44 & 14.74 & 18.19 & 18.77 \\
\hline
\end{tabular}

The sample includes workers aged 18-65 with residence in West Germany and of German nationality (89603 observations). 
Table 7: Trends in Aggregate Skill Inputs by Birth Cohorts

\begin{tabular}{lcccc}
\hline \hline \multicolumn{5}{c}{ Analytical Task Inputs } \\
\hline Year of Birth & 1979 & $1985 / 86$ & $1991 / 92$ & $1998 / 99$ \\
\hline $1975-1981$ & & & & 7.41 \\
$1969-1974$ & & & 7.71 & 11.54 \\
$1962-1968$ & & 5.58 & 10.16 & 14.63 \\
$1956-1961$ & 2.39 & 9.72 & 13.35 & 15.09 \\
$1950-1955$ & 5.15 & 11.16 & 12.69 & 13.95 \\
$1940-1949$ & 5.49 & 11.23 & 11.22 & 15.32 \\
before 1940 & 4.23 & 9.47 & 8.76 & 16.56 \\
\hline \multicolumn{5}{c}{10 x Average Annualized Changes $1979-1998 / 99$} \\
\hline Within Cohorts: & 5.90 & & \\
Within Age Levels: & 4.89 &
\end{tabular}

\begin{tabular}{lcccc}
\hline \hline \multicolumn{5}{c}{ Interactive Task Inputs } \\
\hline Year of Birth & 1979 & $1985 / 86$ & $1991 / 92$ & $1998 / 99$ \\
\hline $1975-1981$ & & & & 23.17 \\
$1969-1974$ & & & 9.52 & 30.35 \\
$1962-1968$ & & 6.25 & 15.05 & 33.61 \\
$1956-1961$ & 5.72 & 10.13 & 18.36 & 34.37 \\
$1950-1955$ & 8.77 & 11.96 & 20.14 & 36.68 \\
$1940-1949$ & 9.90 & 11.95 & 17.81 & 37.26 \\
before 1940 & 8.48 & 10.65 & 14.15 & 36.98 \\
\hline
\end{tabular}

10 x Average Annualized Changes 1979-1998/99

Within Cohorts: 18.33

Within Age Levels: 16.61

\begin{tabular}{lcccc}
\hline \hline \multicolumn{5}{c}{ Routine Cognitive Task Inputs } \\
\hline Year of Birth & 1979 & $1985 / 86$ & $1991 / 92$ & $1998 / 99$ \\
\hline $1975-1981$ & & & & 22.44 \\
$1969-1974$ & & & 22.21 & 21.41 \\
$1962-1968$ & & 25.06 & 28.86 & 24.01 \\
$1956-1961$ & 38.04 & 33.08 & 29.04 & 23.54 \\
$1950-1955$ & 42.08 & 35.72 & 29.69 & 20.57 \\
$1940-1949$ & 39.87 & 33.99 & 27.73 & 19.22 \\
before 1940 & 32.36 & 29.43 & 21.45 & 23.05 \\
\hline
\end{tabular}

10 x Average Annualized Changes 1979-1998/99

Within Cohorts: $\quad-6.11$

Within Age Levels: $\quad-7.0131$ 
$<$ Table 7 continued $>$

\begin{tabular}{|c|c|c|c|c|}
\hline \multicolumn{5}{|c|}{ Routine Manual Task Inputs } \\
\hline Year of Birth & 1979 & $1985 / 86$ & $1991 / 92$ & $1998 / 99$ \\
\hline 1975-1981 & & & & 18.97 \\
\hline 1969-1974 & & & 29.80 & 17.23 \\
\hline 1962-1968 & & 31.51 & 25.23 & 19.15 \\
\hline $1956-1961$ & 41.53 & 27.21 & 24.99 & 17.68 \\
\hline 1950-1955 & 35.13 & 26.05 & 21.80 & 15.19 \\
\hline 1940-1949 & 30.52 & 23.91 & 20.87 & 14.71 \\
\hline before 1940 & 25.21 & 24.80 & 22.91 & 17.61 \\
\hline \multicolumn{5}{|c|}{10 x Average Annualized Changes 1979-1998/99 } \\
\hline Within Cohorts: & -10.47 & & & \\
\hline Within Age Levels: & -8.39 & & & \\
\hline \multicolumn{5}{|c|}{ Non-Routine Manual Task Inputs } \\
\hline Year of Birth & 1979 & $1985 / 86$ & $1991 / 92$ & $1998 / 99$ \\
\hline $1975-1981$ & & & & 30.28 \\
\hline 1969-1974 & & & 25.23 & 27.78 \\
\hline $1962-1968$ & & 22.83 & 22.36 & 25.94 \\
\hline 1956-1961 & 15.42 & 20.78 & 20.18 & 25.69 \\
\hline $1950-1955$ & 14.18 & 18.05 & 18.35 & 25.68 \\
\hline 1940-1949 & 13.39 & 18.91 & 17.31 & 24.45 \\
\hline before 1940 & 14.25 & 19.74 & 19.37 & 23.30 \\
\hline \multicolumn{5}{|c|}{10 x Average Annualized Changes 1979-1998/99 } \\
\hline Within Cohorts: & 4.68 & & & \\
\hline Within Age Levels: & 6.57 & & & \\
\hline
\end{tabular}

The sample includes workers aged 18-65 with residence in West Germany and of German nationality. 
Table 8: Shift-Share Analysis of Changes in Skill Requirements

\begin{tabular}{|c|c|c|c|c|c|c|c|c|c|c|}
\hline \multicolumn{11}{|c|}{$10 \mathrm{x}$ Annual Changes in Task Measures } \\
\hline & \multirow{2}{*}{\multicolumn{2}{|c|}{ analytic }} & \multirow{2}{*}{\multicolumn{2}{|c|}{ interactive }} & \multirow{2}{*}{\multicolumn{2}{|c|}{$\begin{array}{c}\text { routine } \\
\text { cognitive }\end{array}$}} & \multirow{2}{*}{\multicolumn{2}{|c|}{$\begin{array}{l}\text { routine } \\
\text { manual }\end{array}$}} & \multirow{2}{*}{\multicolumn{2}{|c|}{$\begin{array}{c}\text { non-routine } \\
\text { manual }\end{array}$}} \\
\hline & & & & & & & & & & \\
\hline \multicolumn{11}{|c|}{ Overall } \\
\hline $1979-85$ & \multicolumn{2}{|c|}{8.82} & \multicolumn{2}{|c|}{3.35} & \multicolumn{2}{|c|}{-8.43} & \multicolumn{2}{|c|}{-7.83} & \multicolumn{2}{|c|}{9.52} \\
\hline $1985-91$ & \multicolumn{2}{|c|}{2.12} & \multicolumn{2}{|c|}{10.12} & \multicolumn{2}{|c|}{-8.05} & \multicolumn{2}{|c|}{-4.50} & \multicolumn{2}{|c|}{-0.21} \\
\hline 1991-99 & \multicolumn{2}{|c|}{4.21} & \multicolumn{2}{|c|}{24.63} & \multicolumn{2}{|c|}{-6.94} & \multicolumn{2}{|c|}{-8.98} & \multicolumn{2}{|c|}{8.94} \\
\hline 1979-99 & \multicolumn{2}{|c|}{5.01} & \multicolumn{2}{|c|}{13.34} & \multicolumn{2}{|c|}{-7.76} & \multicolumn{2}{|c|}{-7.20} & \multicolumn{2}{|c|}{6.23} \\
\hline \multicolumn{11}{|c|}{ Between and Within Occupational Decomposition } \\
\hline & btwn & wthn & btwn & wthn & btwn & wthn & btwn & wthn & btwn & wthn \\
\hline $1979-85$ & -0.27 & 9.10 & 0.15 & 3.21 & -1.40 & -7.03 & -1.26 & -6.57 & 0.77 & 8.75 \\
\hline 1985-91 & 0.44 & 1.68 & 0.10 & 10.02 & 0.87 & -8.92 & -0.00 & -4.50 & 0.34 & -0.55 \\
\hline 1991-99 & 2.67 & 1.55 & 5.24 & 19.39 & 0.06 & -7.00 & -6.04 & -2.94 & -0.97 & 9.91 \\
\hline 1979-99 & 0.77 & 4.24 & 1.70 & 11.64 & -0.06 & -7.70 & -0.98 & -6.22 & 0.12 & 6.11 \\
\hline
\end{tabular}

The sample includes workers aged 18-65 with residence in West Germany and of German nationality. Occupations are defined according to the 2-digit level of the classification of occupational titles.

Table 9: Distribution of Task Inputs by Education Groups

\begin{tabular}{lccccc}
\hline \hline & $\begin{array}{c}\text { analytic } \\
\text { skills }\end{array}$ & $\begin{array}{c}\text { interactive } \\
\text { skills }\end{array}$ & $\begin{array}{c}\text { routine } \\
\text { cognitive }\end{array}$ & $\begin{array}{c}\text { routine } \\
\text { manual }\end{array}$ & $\begin{array}{c}\text { non-routine } \\
\text { manual skills }\end{array}$ \\
\hline high level of education & 22.72 & 33.98 & 29.91 & 9.76 & 11.13 \\
medium lev. of education & 8.44 & 15.51 & 31.38 & 27.10 & 22.57 \\
low level of education & 4.89 & 7.84 & 21.86 & 23.85 & 13.35 \\
\hline \hline
\end{tabular}

The sample includes workers aged 18-65 with residence in West Germany and of German nationality. 
Table 10: Trends in Aggregate Computer Use and Within Different Educational Groups

\begin{tabular}{lcccc}
\hline \hline \multicolumn{5}{c}{ Spread of Computers, Terminals, Laptops, Electronic Data-Processing Devices } \\
\hline & Overall & Low Level of Education & Medium Level of Education & High Level of Education \\
\hline 1979 & 6.06 & 3.44 & 6.31 & 12.22 \\
$1985 / 86$ & 18.11 & 10.19 & 20.00 & 25.58 \\
$1991 / 92$ & 34.52 & 16.13 & 33.77 & 60.73 \\
$1998 / 99$ & 55.38 & 32.65 & 56.52 & 83.15 \\
\hline \hline
\end{tabular}

The sample includes workers aged 18-65 with residence in West Germany and of German nationality.

Table 11: Spread of Computer Use by Occupational Groups

\begin{tabular}{lcccc}
\hline \hline Occupational Group & 1979 & $1985 / 86$ & $1991 / 92$ & $1998 / 99$ \\
\hline White-collar workers & & & & \\
$\quad$ Professionals, Technical workers, Managers, Administrators & 8.53 & 23.47 & 47.34 & 72.25 \\
$\quad$ Clerical & 12.85 & 43.87 & 70.76 & 91.99 \\
$\quad$ Sales & 3.65 & 15.18 & 23.46 & 45.12 \\
Blue-collar workers & & & & \\
$\quad$ Operatives and Craft People & 1.40 & 4.18 & 12.33 & 27.52 \\
$\quad$ Laborers & 0.52 & 1.82 & 11.17 & 17.11 \\
Personal service workers & 3.03 & 6.79 & 15.30 & 40.99 \\
\hline \hline
\end{tabular}

The sample includes workers aged 18-65 with residence in West Germany and of German nationality. 
Table 12: Bivariate Regressions: Technological Change and Changes in Skill Requirements

\begin{tabular}{|c|c|c|c|c|}
\hline \multicolumn{5}{|c|}{ Dep. Variables: (Annualized Changes in Task Inputs) } \\
\hline & $\Delta$ analytic & $\Delta$ interactive & $\begin{array}{l}\Delta \text { routine } \\
\text { cognitive }\end{array}$ & $\begin{array}{c}\Delta \text { routine } \\
\text { manual }\end{array}$ \\
\hline \multicolumn{5}{|c|}{ Panel A } \\
\hline \multirow[t]{2}{*}{$\Delta$ computer use } & $0.086^{* * *}$ & $0.188^{* * *}$ & $-0.312^{* * *}$ & $-0.561^{* * *}$ \\
\hline & $(0.032)$ & $(0.031)$ & $(0.105)$ & $(0.148)$ \\
\hline \multirow[t]{2}{*}{ dummy 1985/86-1991/92 } & $-6.160^{* * *}$ & $3.536^{* *}$ & -1.960 & -2.462 \\
\hline & $(1.129)$ & $(1.767)$ & $(3.098)$ & $(7.712)$ \\
\hline \multirow[t]{2}{*}{ dummy 1991/92-1998/99 } & $-7.987^{* * *}$ & $8.915^{* * *}$ & $16.394^{* *}$ & -7.436 \\
\hline & $(1.381)$ & $(1.440)$ & $(7.726)$ & $(7.065)$ \\
\hline$R^{2}$ & 0.183 & 0.337 & 0.079 & 0.131 \\
\hline Number of observations: & \multicolumn{4}{|c|}{237} \\
\hline \multicolumn{5}{|c|}{ Panel B } \\
\hline \multirow[t]{2}{*}{ Lagged $\Delta$ computer use } & -0.022 & $0.160^{* * *}$ & $-0.796^{* * *}$ & $-0.173^{* * *}$ \\
\hline & $(0.035)$ & $(0.031)$ & $(0.202)$ & $(0.065)$ \\
\hline \multirow[t]{2}{*}{ dummy 1985/86-1991/92 } & 1.470 & $-4.632^{* * *}$ & $-23.444^{* * *}$ & $6.005^{*}$ \\
\hline & $(1.350)$ & $(1.703)$ & $(7.237)$ & $(3.637)$ \\
\hline$R^{2}$ & 0.015 & 0.195 & 0.205 & 0.053 \\
\hline Number of observations: & \multicolumn{4}{|c|}{156} \\
\hline Weighted mean dependent variable & 0.425 & 0.980 & -0.849 & -0.504 \\
\hline
\end{tabular}

Ro $\overline{\overline{b u s t} \text { standard errors are in parentheses; regressions are weighted by the number of individuals }}$ within occupation group; ${ }^{* * *},{ }^{* *},{ }^{*}$-indicate significance at the 1, 5, 10 percent level. 
Table 13: Changes in Skill Requirements and Changes in the Educational and Gender Distribution

\begin{tabular}{|c|c|c|c|c|}
\hline & $\Delta$ analytic & $\Delta$ interactive & $\begin{array}{l}\Delta \text { routine } \\
\text { cognitive }\end{array}$ & $\begin{array}{c}\Delta \text { routine } \\
\text { manual }\end{array}$ \\
\hline \multicolumn{5}{|c|}{ Panel A } \\
\hline$\Delta$ computer use & $\begin{array}{c}0.076^{* * *} \\
(0.031)\end{array}$ & $\begin{array}{c}0.181^{* * *} \\
(0.033)\end{array}$ & $\begin{array}{c}-0.311^{* * *} \\
(0.108)\end{array}$ & $\begin{array}{c}-0.529^{* * *} \\
(0.163)\end{array}$ \\
\hline$\Delta$ Proportion w/ & $0.064^{* *}$ & $0.081^{* *}$ & $-0.195^{*}$ & 0.049 \\
\hline high educ. level & $(0.033)$ & $(0.039)$ & $(0.115)$ & $(0.178)$ \\
\hline$\Delta$ Proportion w/ & 0.006 & 0.038 & $-0.177^{*}$ & 0.257 \\
\hline medium educ. level & $(0.025)$ & $(0.034)$ & $(0.104)$ & $(0.184)$ \\
\hline$\Delta$ Proportion & $-0.119^{* * *}$ & 0.026 & $-0.607^{* * *}$ & -0.068 \\
\hline female employees & $(0.049)$ & $(0.049)$ & $(0.191)$ & $(0.175)$ \\
\hline$R^{2}$ & 0.222 & 0.348 & 0.112 & 0.148 \\
\hline Number of observations: & \multicolumn{4}{|c|}{237} \\
\hline
\end{tabular}

\begin{tabular}{lcccc}
\hline \hline \multicolumn{5}{c}{ Panel B } \\
\hline Lagged $\Delta$ computer use & -0.009 & $0.153^{* * *}$ & $-0.752^{* * *}$ & $-0.187^{* * *}$ \\
& $(0.032)$ & $(0.031)$ & $(0.211)$ & $(0.072)$ \\
Lagged $\Delta$ Proportion w/ & -0.056 & 0.011 & $-0.680^{* * *}$ & $0.244^{* * *}$ \\
high educ. level & $(0.067)$ & $(0.048)$ & $(0.195)$ & $(0.094)$ \\
Lagged $\Delta$ Proportion w/ & -0.015 & $-0.103^{*}$ & -0.123 & $0.145^{* *}$ \\
medium educ. level & $(0.036)$ & $(0.060)$ & $(0.140)$ & $(0.066)$ \\
Lagged $\Delta$ Proportion & 0.110 & $0.177^{* * *}$ & $-0.714^{* * *}$ & 0.045 \\
female employees & $(0.068)$ & $(0.054)$ & $(0.268)$ & $(0.178)$ \\
\hline$R^{2}$ & 0.059 & 0.274 & 0.275 & 0.084 \\
\hline Number of observations: & \multicolumn{5}{c}{156} \\
\hline
\end{tabular}

Control variables are: time dummies. Robust standard errors are in parentheses. Regressions are weighted by the number of individuals within occupation group. ${ }^{* * *},{ }^{* *},{ }^{*}$-indicate significance at the 1, 5, 10 percent level. 
Table 14: Technological Change and Changes in Skill Requirements by Education

\begin{tabular}{|c|c|c|c|c|}
\hline & $\Delta$ analytic & $\Delta$ interactive & $\begin{array}{l}\Delta \text { routine } \\
\text { cognitive }\end{array}$ & $\begin{array}{c}\Delta \text { routine } \\
\text { manual }\end{array}$ \\
\hline \multicolumn{5}{|c|}{ Employees with High Level of Education } \\
\hline \multirow[t]{2}{*}{$\Delta$ computer use } & 0.027 & 0.058 & $-0.253^{* *}$ & -0.052 \\
\hline & $(0.065)$ & $(0.060)$ & $(0.120)$ & $(0.077)$ \\
\hline \multirow[t]{2}{*}{ dummy 1985/86-1991/92 } & -0.356 & $17.304^{* * *}$ & -10.983 & 0.393 \\
\hline & $(4.368)$ & $(4.483)$ & $(7.911)$ & $(7.312)$ \\
\hline \multirow[t]{2}{*}{ dummy 1991/92-1998/99 } & $-9.898^{* * *}$ & $10.594^{* * *}$ & $-17.912^{* *}$ & 4.761 \\
\hline & $(3.870)$ & $(3.987)$ & $(8.395)$ & $(6.494)$ \\
\hline$R^{2}$ & 0.084 & 0.171 & 0.084 & 0.010 \\
\hline \multicolumn{2}{|l|}{ Number of observations: } & \multicolumn{2}{|c|}{121} & \\
\hline \multicolumn{5}{|c|}{ Employees with Medium Level of Education } \\
\hline \multirow[t]{2}{*}{$\Delta$ computer use } & $0.069^{*}$ & $0.127^{* * *}$ & -0.131 & $-0.521^{* * *}$ \\
\hline & $(0.040)$ & $(0.029)$ & $(0.114)$ & $(0.171)$ \\
\hline \multirow[t]{2}{*}{ dummy 1985/86-1991/92 } & $-7.465^{* * *}$ & $2.646^{*}$ & -2.880 & -3.525 \\
\hline & $(1.159)$ & $(1.628)$ & $(3.243)$ & $(8.226)$ \\
\hline \multirow[t]{2}{*}{ dummy 1991/92-1998/99 } & $-8.208^{* * *}$ & $10.095^{* * *}$ & $18.047^{* *}$ & -9.451 \\
\hline & $(1.400)$ & $(1.481)$ & $(8.854)$ & $(8.006)$ \\
\hline$R^{2}$ & 0.186 & 0.299 & 0.067 & 0.113 \\
\hline \multicolumn{2}{|l|}{ Number of observations: } & \multicolumn{2}{|c|}{234} & \\
\hline
\end{tabular}

\begin{tabular}{lcccc}
\hline \hline \multicolumn{5}{c}{ Employees with Low Level of Education } \\
\hline$\Delta$ computer use & $0.128^{* * *}$ & $0.151^{* * *}$ & $-0.196^{*}$ & $-0.309^{* * *}$ \\
& $(0.042)$ & $(0.044)$ & $(0.120)$ & $(0.129)$ \\
dummy 1985/86-1991/92 & $-3.685^{* * *}$ & 0.230 & 1.498 & -2.267 \\
& $(1.176)$ & $(1.762)$ & $(3.814)$ & $(7.916)$ \\
dummy 1991/92-1998/99 & $-5.472^{* * *}$ & $4.760^{* * *}$ & $31.453^{* * *}$ & $-11.904^{* *}$ \\
& $(1.438)$ & $(1.616)$ & $(7.780)$ & $(6.445)$ \\
\hline$R^{2}$ & 0.149 & 0.148 & 0.161 & 0.056 \\
\hline Number of observations: & \multicolumn{5}{c}{226} \\
\hline \hline
\end{tabular}

Robust standard errors are in parentheses. Regressions are weighted by the number individuals within occupation group. ${ }^{* * *},{ }^{* *},{ }^{*}$-indicate significance at the $1,5,10$ percent level. 
Table 15: Technological Change and Changes in Skill Requirements by Birth Cohort

\begin{tabular}{|c|c|c|c|c|}
\hline & $\Delta$ analytic & $\Delta$ interactive & $\begin{array}{l}\Delta \text { routine } \\
\text { cognitive }\end{array}$ & $\begin{array}{c}\Delta \text { routine } \\
\text { manual }\end{array}$ \\
\hline \multicolumn{5}{|c|}{ Employees born between 1956 and 1961} \\
\hline \multirow[t]{2}{*}{$\Delta$ computer use } & $0.113^{* * *}$ & $0.152^{* * *}$ & -0.202 & $-0.647^{* * *}$ \\
\hline & $(0.034)$ & $(0.041)$ & $(0.130)$ & $(0.171)$ \\
\hline \multirow[t]{2}{*}{ dummy 1985/86-1991/92 } & $-5.231 * * *$ & 3.543 & 0.378 & 5.933 \\
\hline & $(1.561)$ & $(2.229)$ & $(4.923)$ & $(9.799)$ \\
\hline \multirow[t]{2}{*}{ dummy 1991/92-1998/99 } & $-10.853^{* * *}$ & $5.416^{* * *}$ & 14.226 & -1.759 \\
\hline & $(1.675)$ & $(1.685)$ & $(8.869)$ & $(9.112)$ \\
\hline$R^{2}$ & 0.205 & 0.118 & 0.036 & 0.117 \\
\hline \multicolumn{2}{|l|}{ Number of observations: } & \multicolumn{2}{|c|}{220} & \\
\hline \multicolumn{5}{|c|}{ Employees born between 1950 and 1955} \\
\hline \multirow[t]{2}{*}{$\Delta$ computer use } & 0.049 & $0.216^{* * *}$ & $-0.226^{* *}$ & $-0.513^{* * *}$ \\
\hline & $(0.044)$ & $(0.055)$ & $(0.111)$ & $(0.160)$ \\
\hline \multirow[t]{2}{*}{ dummy 1985/86-1991/92 } & $-4.805^{* *}$ & $6.301^{* * *}$ & -3.230 & -3.639 \\
\hline & $(1.878)$ & $(2.249)$ & $(4.407)$ & $(8.854)$ \\
\hline \multirow[t]{2}{*}{ dummy 1991/92-1998/99 } & $-8.950^{* * *}$ & $7.753^{* * *}$ & 11.791 & -10.845 \\
\hline & $(1.960)$ & $(2.062)$ & $(8.977)$ & $(7.960)$ \\
\hline$R^{2}$ & 0.092 & 0.178 & 0.047 & 0.087 \\
\hline \multicolumn{2}{|l|}{ Number of observations: } & \multicolumn{2}{|c|}{211} & \\
\hline \multicolumn{5}{|c|}{ Employees born between 1940 and 1949} \\
\hline \multirow[t]{2}{*}{$\Delta$ computer use } & $0.111^{* * *}$ & $0.203^{* * *}$ & $-0.255^{* *}$ & $-0.411^{* * *}$ \\
\hline & $(0.030)$ & $(0.041)$ & $(0.113)$ & $(0.130)$ \\
\hline \multirow[t]{2}{*}{ dummy 1985/86-1991/92 } & $-7.972^{* * *}$ & 2.846 & -5.388 & -3.357 \\
\hline & $(1.504)$ & $(2.010)$ & $(3.765)$ & $(8.137)$ \\
\hline \multirow[t]{2}{*}{ dummy 1991/92-1998/99 } & $-7.210^{* * *}$ & $10.067^{* * *}$ & 9.019 & -8.326 \\
\hline & $(1.773)$ & $(1.755)$ & $(7.841)$ & $(7.244)$ \\
\hline$R^{2}$ & 0.170 & 0.280 & 0.059 & 0.071 \\
\hline Number of observations: & \multicolumn{4}{|c|}{224} \\
\hline
\end{tabular}


$<$ Table 15 continued $>$

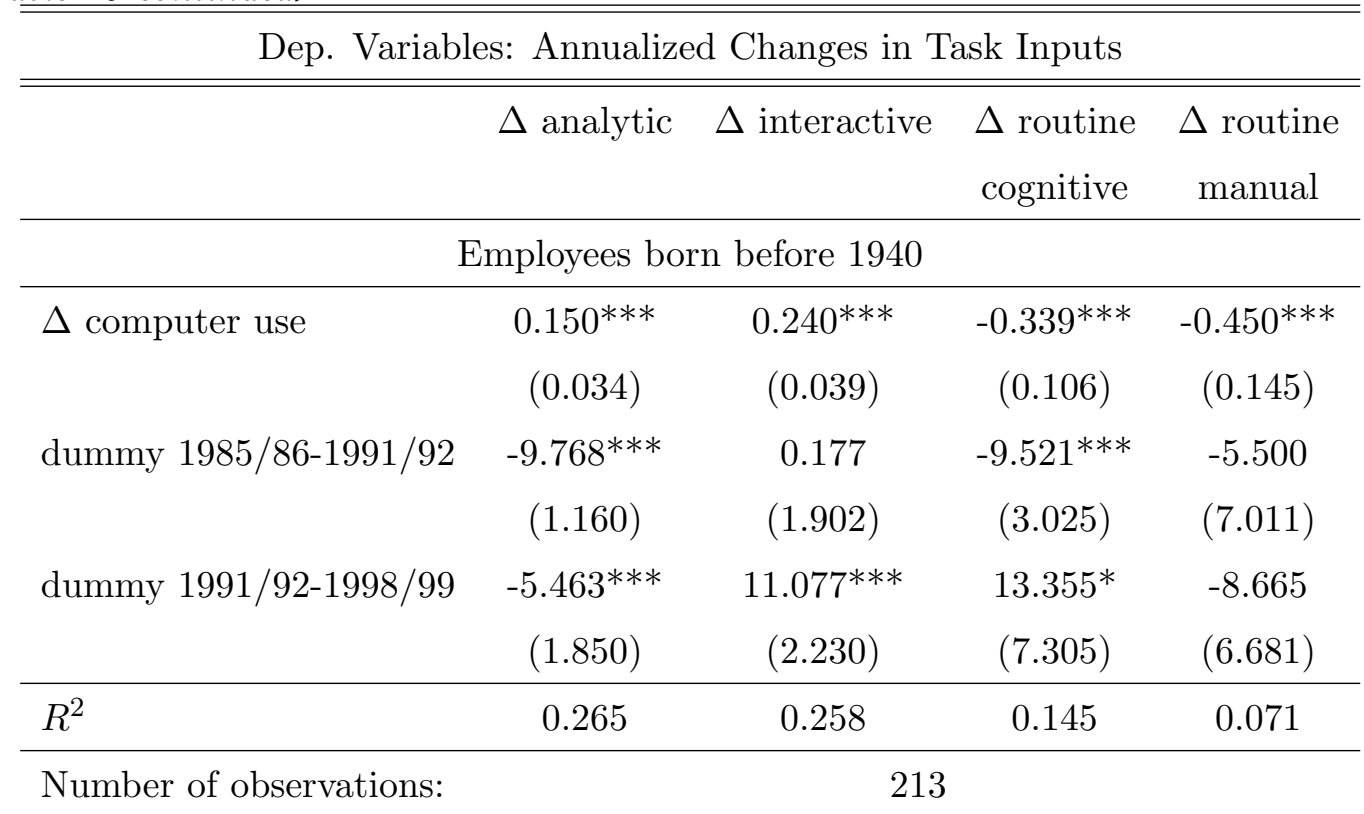

Robust standard errors are in parentheses. Regressions are weighted by the number of individuals within occupation group. ${ }^{* * *},{ }^{* *},{ }^{*}$-indicate significance at the $1,5,10$ percent level. 
Table 16: OLS Results: Educational Requirements within Occupation Group as a Function of Task Inputs

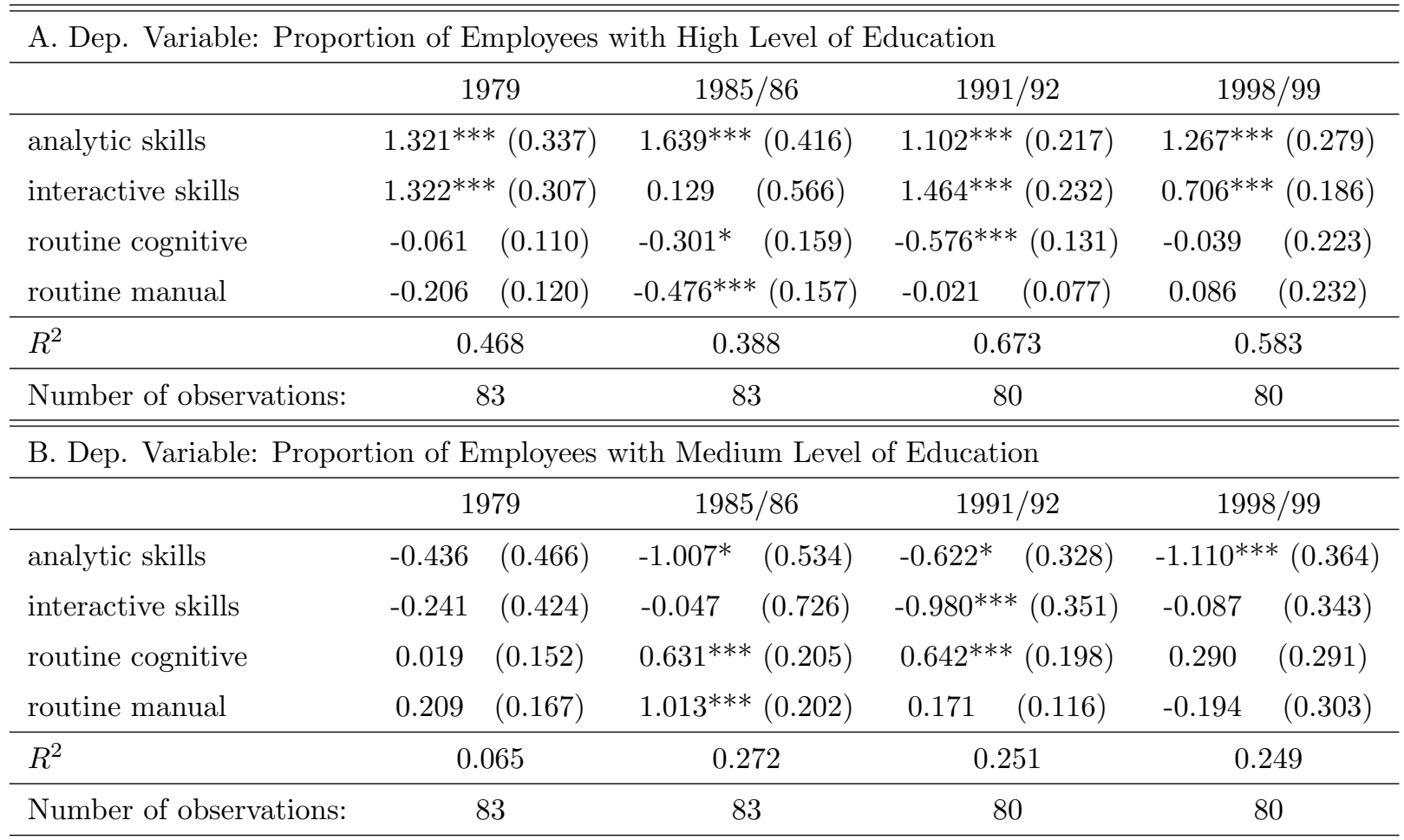

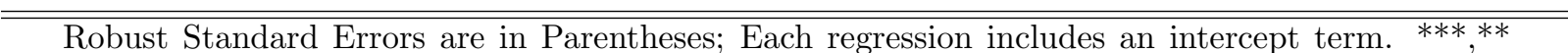
indicate significance at the 1,5 percent level. 
Table 17: Shifts in High-Educated-Equivalent Labor Demand and Medium-EducatedEquivalent Labor Demand Implied by Changes in Occupational Skill Requirement

\begin{tabular}{|c|c|c|c|c|}
\hline & $1979-1985 / 86$ & $1985 / 86-1991 / 92$ & $1991 / 92-1998 / 99$ & $1979-1998 / 99$ \\
\hline \multicolumn{5}{|c|}{ A. 10 x Observed Annual Changes in the Proportion of Employees with... } \\
\hline High Level of Education & 3.667 & 5.333 & 5.167 & 4.250 \\
\hline Medium Level of Education & -6.833 & 5.000 & -1.167 & -0.947 \\
\hline \multicolumn{5}{|c|}{ B. 10 x Observed Annual Changes in Within Occupation Skill Requirements } \\
\hline analytic skills & 9.037 & 1.716 & 1.774 & 4.242 \\
\hline interactive skills & 3.046 & 9.981 & 16.430 & 10.705 \\
\hline routine cognitive & -6.059 & -9.054 & -10.416 & -8.965 \\
\hline routine manual & -5.875 & -5.216 & -4.028 & -7.305 \\
\hline \multicolumn{5}{|c|}{ C. Predicted Proportion of Changes in the Share of Employees with High (Medium) Level of Education } \\
\hline \multicolumn{5}{|c|}{ Explained by Observed Changes in Within Occupation Skill Requirements (in Percent) } \\
\hline High Level of Education & 47.934 & 32.237 & 49.741 & 48.997 \\
\hline Medium Level of Education & 8.815 & -8.834 & 49.463 & 64.698 \\
\hline
\end{tabular}

D. Predicted Annual Changes in Occupation Skill Requirements Implied by Computerization (10 x Annual Changes)

\begin{tabular}{lcccc}
\hline analytic skills & 8.901 & 2.991 & 0.519 & 4.129 \\
interactive skills & 4.243 & 9.572 & 15.013 & 9.664 \\
routine cognitive & -5.547 & -9.001 & 6.519 & -2.375 \\
routine manual & 2.171 & -0.134 & -4.503 & -0.964 \\
\hline
\end{tabular}

E. Predicted Proportion of Changes in the Share of Employees with High/Medium Level of Education Explained by Predicted Changes in Occupation Skill Requirements Implied by Computerization (in Percent)

\begin{tabular}{lcccc}
\hline High Level of Education & 47.184 & 32.298 & 47.900 & 41.736 \\
Medium Level of Education & 6.669 & -7.506 & 46.546 & 46.171 \\
\hline \hline
\end{tabular}


Table 18: Trends in Occupational Skill Requirements for Occupations Grouped by the 1979 Value of the Skill Index

\begin{tabular}{|c|c|c|c|c|}
\hline & 1979 & $1985 / 86$ & $1991 / 92$ & $1998 / 99$ \\
\hline \multicolumn{5}{|c|}{ First Quartile } \\
\hline Mean Value of the Skill Index & -3.758 & 18.295 & 23.334 & 49.587 \\
\hline Proportion of empl. w/ high education & 1.059 & 2.638 & 6.672 & 8.462 \\
\hline Proportion of empl. w/ medium education & 72.510 & 72.056 & 74.962 & 77.096 \\
\hline Proportion of empl. w/ low education & 26.431 & 25.306 & 18.367 & 14.443 \\
\hline \multicolumn{5}{|c|}{ Second Quartile } \\
\hline Mean Value of the Skill Index & 0.824 & 1.910 & 2.493 & 13.154 \\
\hline Proportion of empl. w/ high education & 0.324 & 0.428 & 0.570 & 1.000 \\
\hline Proportion of empl. w/ medium education & 71.563 & 69.369 & 74.571 & 77.200 \\
\hline Proportion of empl. w/ low education & 28.113 & 30.203 & 24.859 & 21.803 \\
\hline \multicolumn{5}{|c|}{ Third Quartile } \\
\hline Mean Value of the Skill Index & 7.340 & 13.895 & 24.942 & 43.184 \\
\hline Proportion of empl. w/ high education & 0.806 & 1.879 & 3.723 & 4.115 \\
\hline Proportion of empl. w/ medium education & 81.227 & 78.033 & 82.173 & 81.908 \\
\hline Proportion of empl. w/ low education & 17.967 & 20.088 & 14.104 & 13.977 \\
\hline \multicolumn{5}{|c|}{ Fourth Quartile } \\
\hline Mean Value of the Skill Index & 32.704 & 44.750 & 68.486 & 86.740 \\
\hline Proportion of empl. w/ high education & 32.504 & 33.218 & 45.437 & 47.270 \\
\hline Proportion of empl. w/ medium education & 51.908 & 48.423 & 48.842 & 47.787 \\
\hline Proportion of empl. w/ low education & 15.588 & 18.359 & 5.721 & 4.942 \\
\hline
\end{tabular}

Table 19: Employment Trends for Occupations Grouped by the 1979 Value of the Skill Index

\begin{tabular}{lcccc}
\hline \hline & 1979 & $1985 / 86$ & $1991 / 92$ & $1998 / 99$ \\
\hline First Quartile & 26.93 & 23.38 & 23.59 & 22.42 \\
Second Quartile & 18.43 & 18.54 & 17.87 & 13.97 \\
Third Quartile & 32.21 & 35.10 & 35.44 & 35.64 \\
Fourth Quartile & 22.43 & 22.98 & 23.10 & 27.97 \\
\hline
\end{tabular}


Figure 1: Trends in Aggregate Skill Inputs

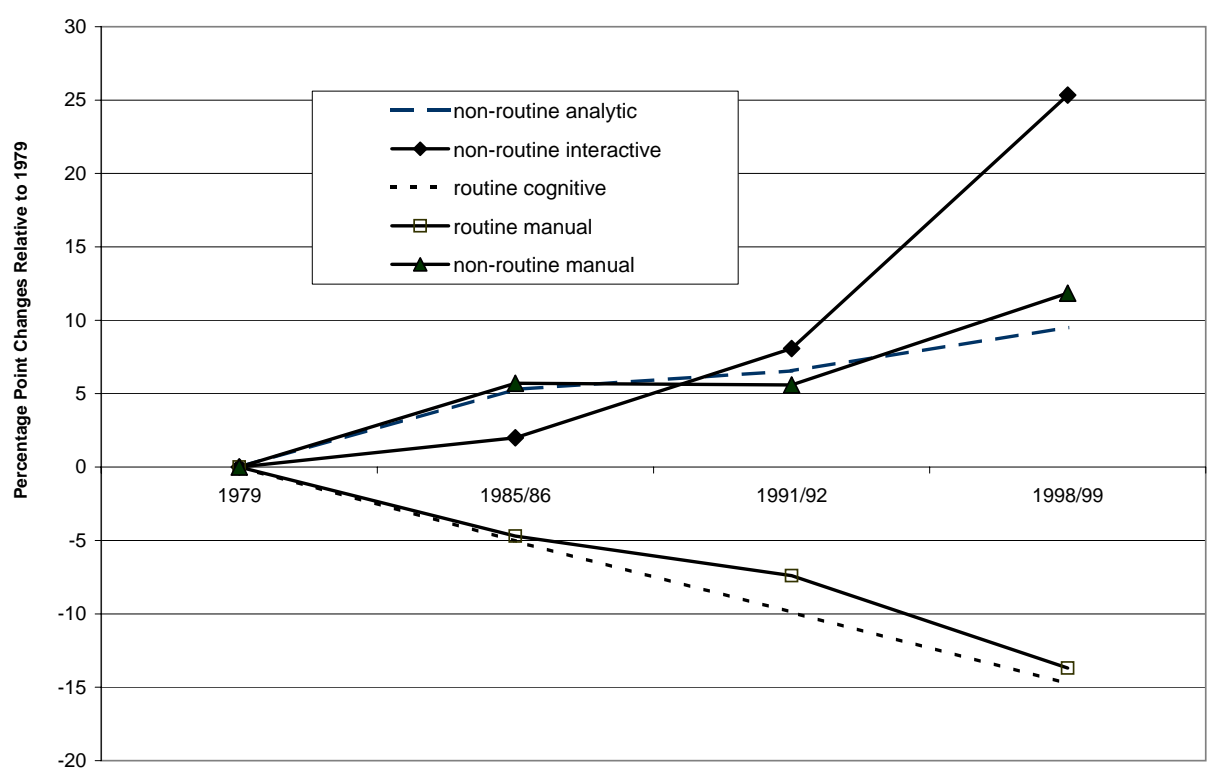

Figure 2: Employees with High Levels of Education: Trends in Aggregate Skill Inputs

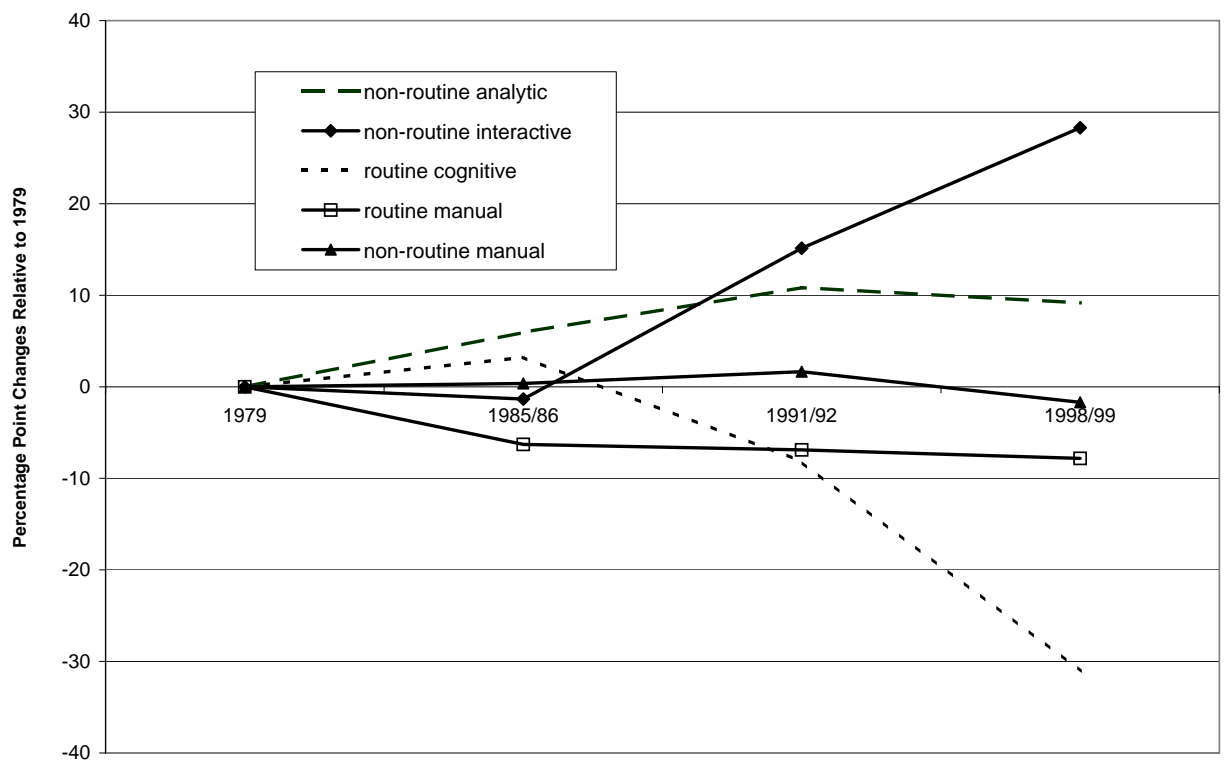


Figure 3: Employees with Medium Levels of Education: Trends in Aggregate Skill Inputs

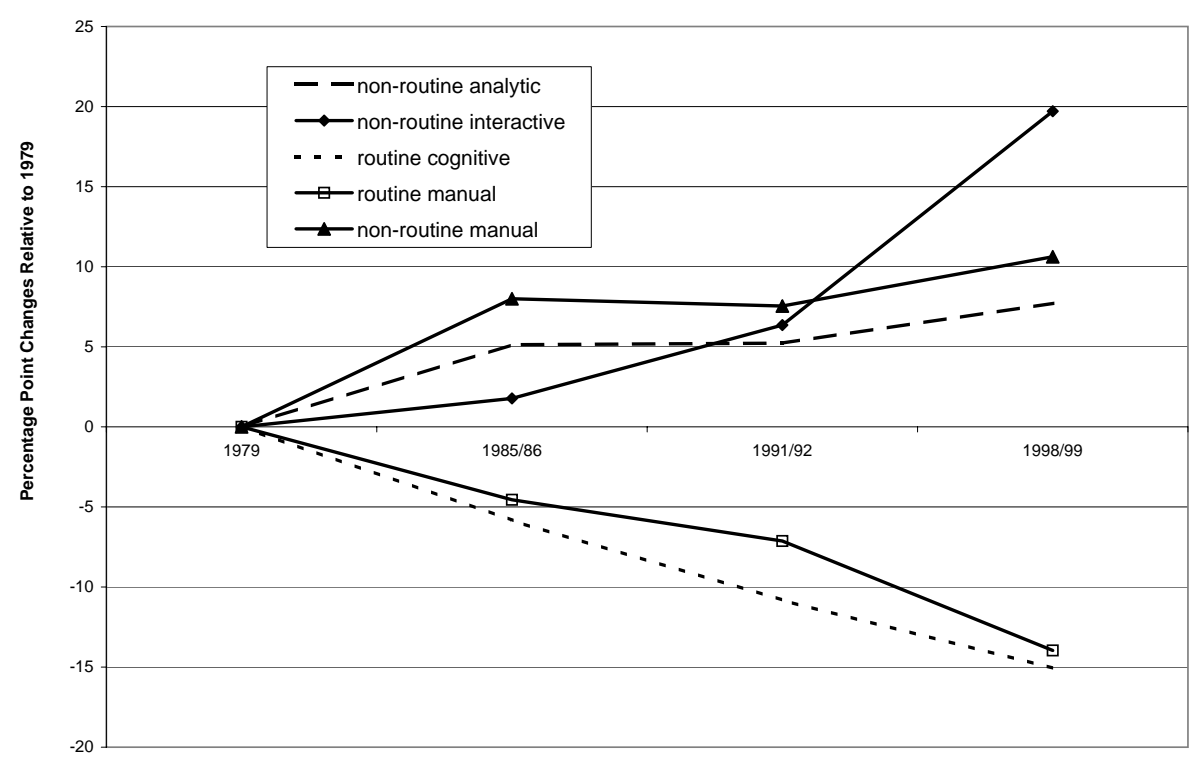

Figure 4: Employees with Low Levels of Education: Trends in Aggregate Skill Inputs

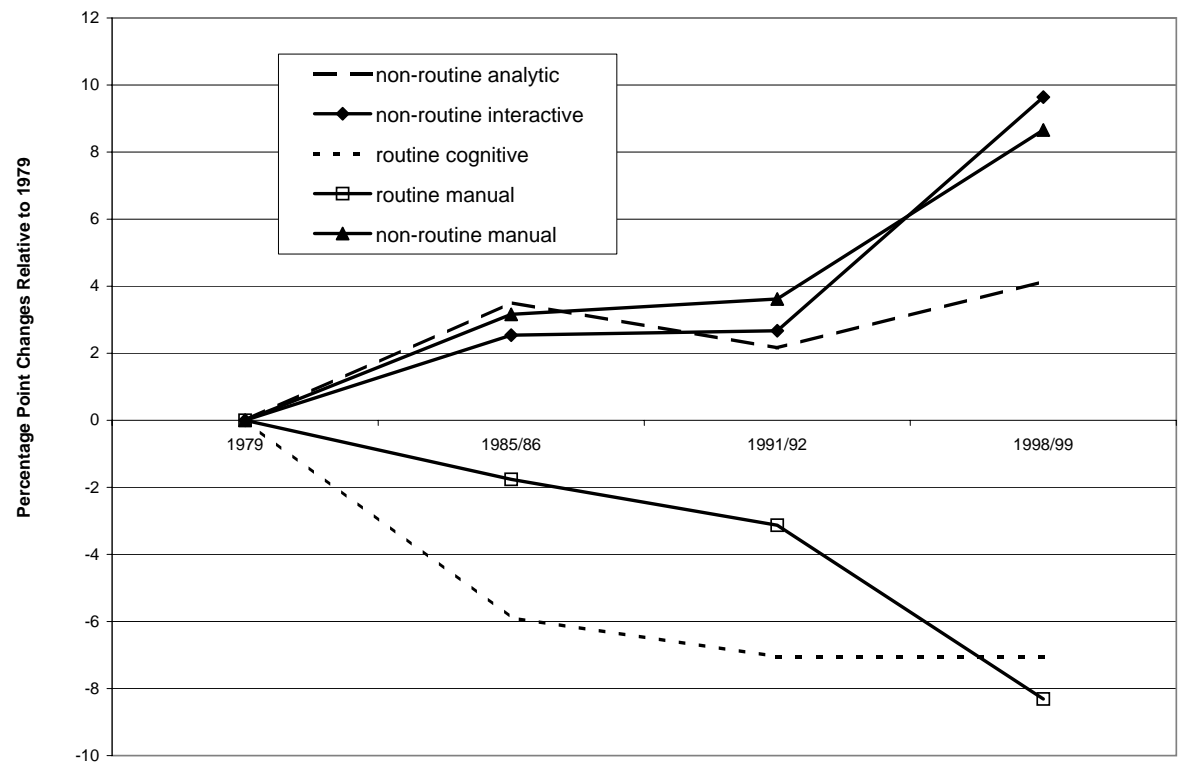


Figure 5: Occupations in the First Quartile

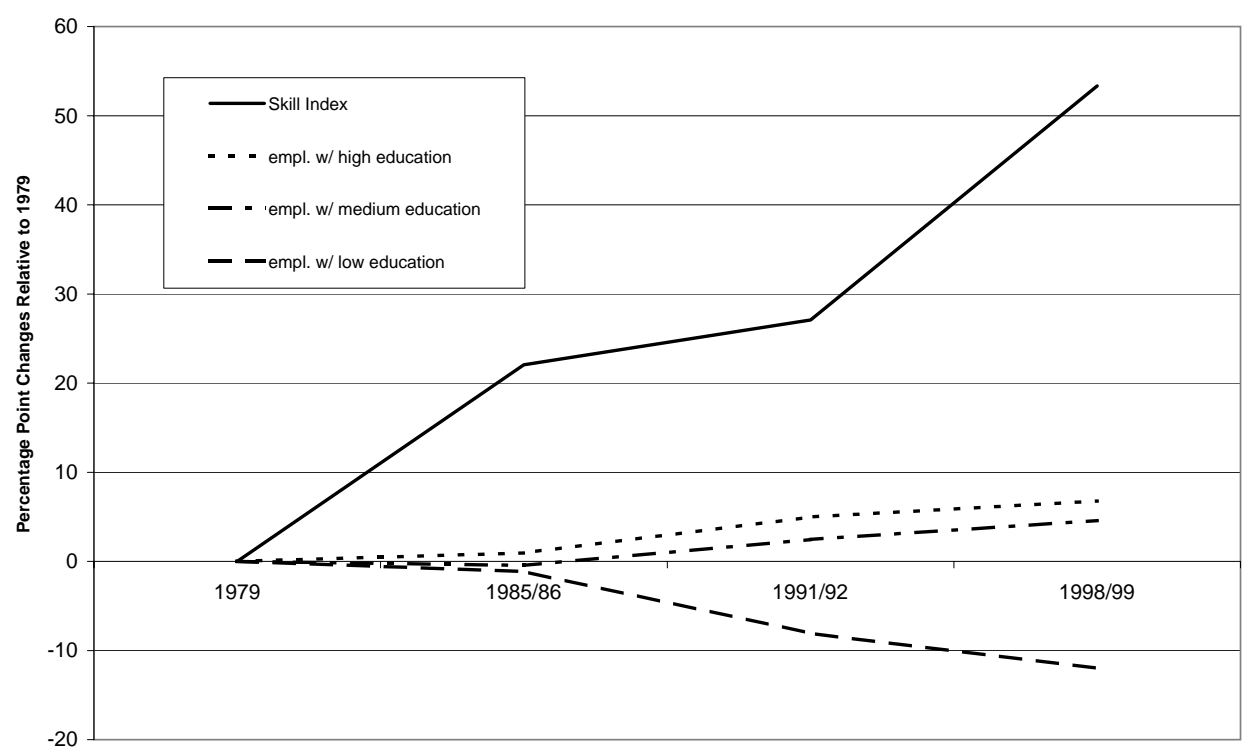

Figure 6: Occupations in the Second Quartile

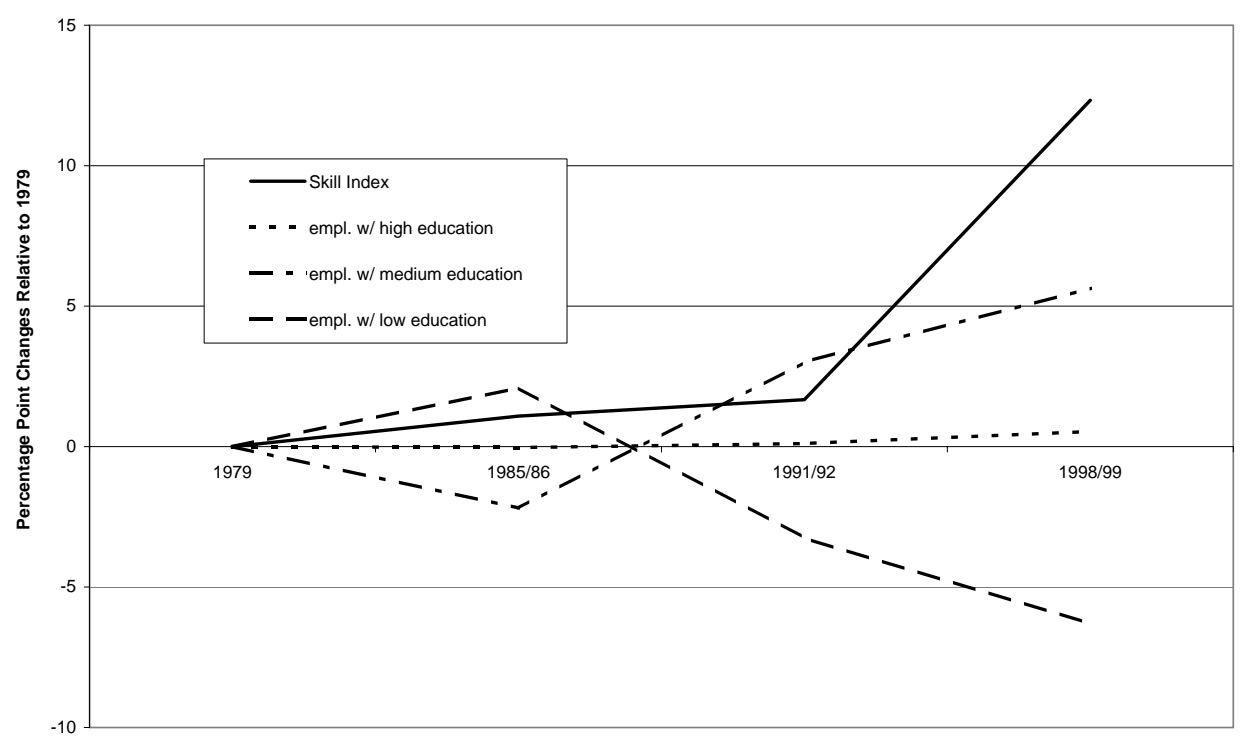


Figure 7: Occupations in the Third Quartile

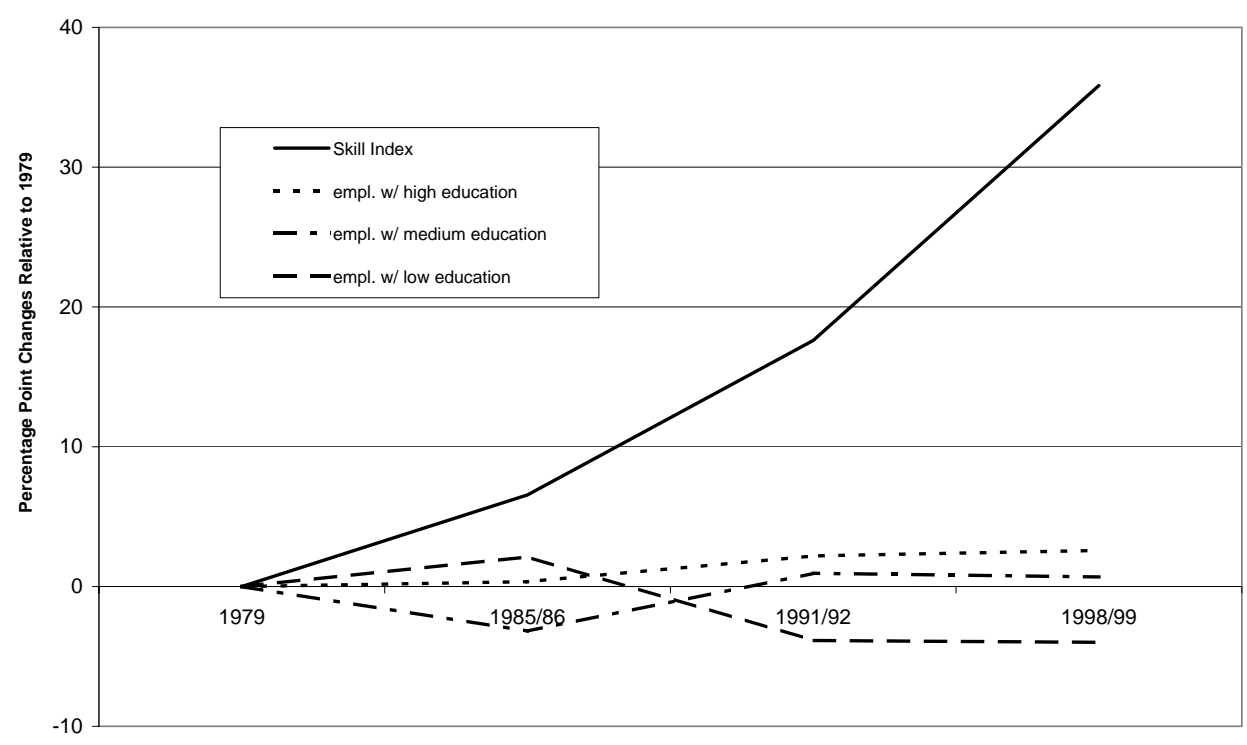

Figure 8: Occupations in the Fourth Quartile

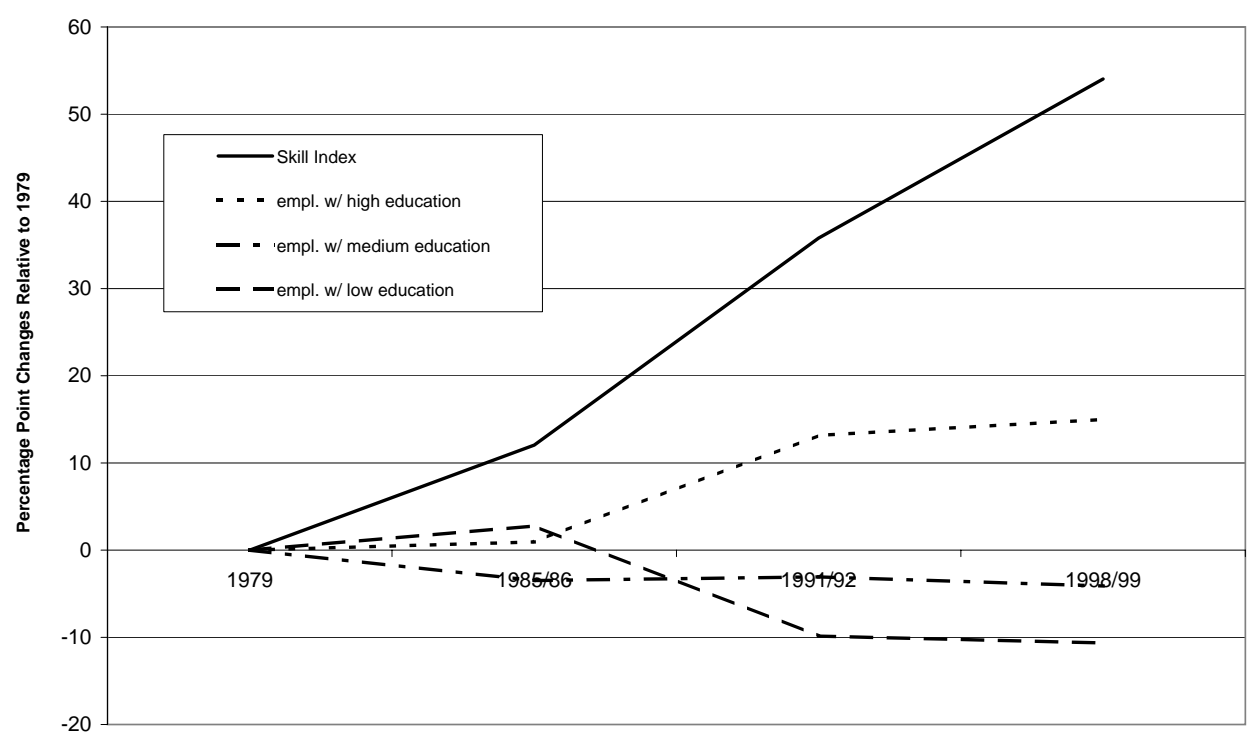


Figure 9: Employment Trends in Occupations Grouped by the 1979 Value of the Skill Index

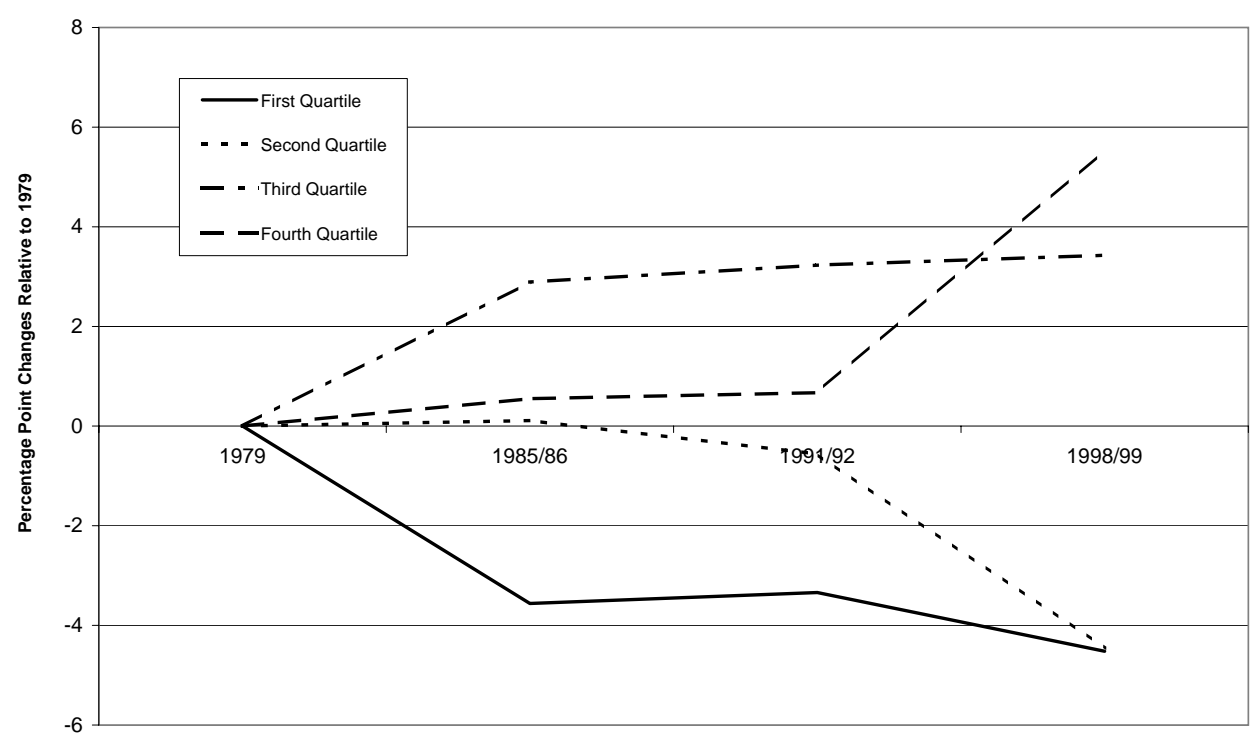

